University of Rhode Island

DigitalCommons@URI

Open Access Master's Theses

1974

\title{
A Direct Comparison of Four Response Elimination Procedures in Rats
}

William A. Pacitti

University of Rhode Island

Follow this and additional works at: https://digitalcommons.uri.edu/theses

\section{Recommended Citation}

Pacitti, William A., "A Direct Comparison of Four Response Elimination Procedures in Rats" (1974). Open Access Master's Theses. Paper 1612.

https://digitalcommons.uri.edu/theses/1612

This Thesis is brought to you for free and open access by DigitalCommons@URI. It has been accepted for inclusion in Open Access Master's Theses by an authorized administrator of DigitalCommons@URI. For more information, please contact digitalcommons-group@uri.edu. 
A DIRECT COMPARISON OF FOUR RESPONSE

EIMMINATION PROCEDURES IN RATS

BY

WILLIAM A. PACITTI

A THESIS SUBMITTED IN PARTIAL FULFILLMENT OF THE REQUIREMENTS FOR THE DEGREE OF

MASTER OF ARTS

IN

PSYCHOLOGY

UNIVERSITY OF RHODE ISLAND

1974 


\section{ABSTRACT}

Thirty two rats received training on a VI 30 second reinforcement schedule and were then shifted to one of four response elimination procedures: Extinction Training, Differential Reinforcement of Other Behavior, Counter-conditioning of a Different Response, and Counter-conditioning of a Similar Response. Nvaluated in terms of efficiency (number of original responses made during Treatment) and durability (number of original responses made in Test and Reconditioning Phases), Counter-conditioning a similar response emerged as the least efficient response elimination procedure and the least durable. Extinction Training was low in eificiency, but relatively more durable than both Counter-conditioning techniques. Counter-conditioning a Different Response was intermediate in terms of efficiency but low in durability, while Differential Reinforcement of Other Behavior resulted in the best responseelimination. 


\section{TABLE OF CONTENTS}

\section{Chapter}

I. Introduction . . . . . . . . . . . 1

II. Method . . . . . . . . . . . . . . 21

III. Results . . . . . . . . . . . . . . . . . . 24

IV. Discussion . . . . . . . . . . . . . 53

\section{APPENDICES}

Appendix A Two Factor Mixed Design

Analysis of Variance Summary Table . . . 65

Appendix B Mean Number of Responses for

Each Subject on Each Manipulandum. . . 56

REFERENCES . . . . . . . . . . . . .70 


\section{LIST OF FIGURES}

Figure

Page

1. Mean Number of Lever A Responses during Each Training Session . . . . . 26

2. Mean Number of Lever A. Responses during each Treatment Day . . . . . . 28

3. Mean Number of Lever A Responses during each Test Day . . . . . . . . 31

4. Mean Number of Lever A Responses for each Group during the Reconditioning Session . . . . . . . . . . . . . 35

5. Total Number of IJever B Responses during each day of Training, Treatment, and Test Phases . . . . . . . . . . 40

6. Total Number of Pole Pushes during each day of Training, Treatment, and Test Phases . . . . . . . . . . . . . 46 


\section{LIST OF TABLES}

Table

Page

1. Mean Number and Standard Deviations of Lever A Responses for Each Group over five Training Sessions . . . . . . . . . 25

2. Mean Number and Standard Deviations of Lever A Responses for each Group over five Tratment Sessions... . . . . . . 29

3. Mean Number and Standard Deviations of Lever A for each Group over five Test Sessions . . . . . . . . . . . . . . 33

4. Mann-Whitney U-Tests: Number of Lever

A Responses in Test phase . . . . . . . . . 34

5. Mean Number and Standard Deviations of Lever A Responses in Peconditioning Session . . . . . . . . . . . . 36

6. Mann-Whitney U Tests: Number of Lever A Responses in keconditioning Session . . . . 38

7. Mann-Whitney $\mathrm{T}$-Tests: Overall Number of Lever A Responses in Treatment and Test Phases Combined ........... . . 39

8. Mean Number and Standard Deviations of Lever B Responses for each Group over five Training Sessiolis . . . . . . . . . 41

9. Mann-Whitney U-Tests: Number of Lever $B$ Responses in Training Phase . . . . . 
10. Mean Number and Standard Deviations of Lever B Responses for each Group over Five Treatrnent Sessions . . . . . . . 43

11. Marn-Whitriey U-Tests: Number of Lever B Responses in Treatment Phase. . . . . 44

12. Mean Number and Standard Deviations of Lever B Responses for each Group over Five Test Sessions......... . 45

13. Mann-Whitney U-Tests: Number of Lever B Responses in Test Phase. . . . . . . 45

14. Mean Number of Pole Pushes and Standard Deviations for each Group during Training 47 Phase . . . . . . . . . . . . . .

15. Mean IJumber of Pole Pushes and Standard Deviations for each Group during Treatment Phase. . . . . . . . . . . . 49

16. Mann-Whitney U-Tests: Number of Pole Pushes in Treatment Phase . . . . . . 50

17. INean Number of Pole Pushes and Standard Deviations for each Group in Test Phase. . .51

18. Mann-Whitney U-Tests: Number of Pole Pushes in Test Phase . . . . . . . . . . 52 
A tas'z confronted by many psychologists interested in applied behavioral control involves eliminating an undesirable or inappropriate response from a subject's repertoire without resorting to aversive stimulation. As Zeiler pointed out in 1971 , relatively little information concerning the comparative efficacy of response elimination procedures excluding punishment is available in the literature, this is still true in 1974.

Extinction, the traditional method of response elimination, predicts that the frequency of a response which has been reiniorced declines when reinforcement is discontinued. Extincticn is commonly regarded as a most effective method of eliminating responding in terms of long lasting results. While discontinuing reinforcemeilt in a laboratory setting is relatively easy to carry out, it becomes aecidedly more difficult as one moves out of the controlied setting of the laboratory to more natural environments. The most difficult problem to overcome in using extinction in applied bchavior change programs is the difficuity encountered in maintaining: consistent nonreinforcement contingencies. Another problem involves the slowiess of the procedure as extinction often takes a substantial length of time to effectively eliminate a response.

Thus, extinction may be classified as a durable method of response elimination as its effects are iong lasting. It cannot, however, be ralled an efficient method for it does not eliminate respond- 
ing quickly.

If extinction is used in conjunction with a rather severe punishment, it will serve to suppress responding rather quickly (Boe \& Church, 1967; Leitenberg \& Fawson, 1973). Response elimination has also been reported to be facilitated without the use of noxious stimulation if another competing or incompatible behavior is reinforced as the original behavior is extinguished (Boe, 1964). The possible acquisition of competing behavior has been suggested in several thecretical explanations of the suppressive effects of extinction (Guthrie, 1952; Weinstock, 1954; Amsel, 1948; Denny, 197. These competing responses have typically been hypothetical rather than directly observed (Koppenal \& Jagoda, 1968), and it has not been clear where they came from, how they were maintained, or what happened to the cld response (Kimble, 1961; Deese \& Hulse, 1967).

Work with concurrent operants, however, indicates that reinforcement for one response can inhibit the other responses (Catania, 1966, 1969). Thus Boe (1964) suggested that extinction might be made more effective if a reinforceci alternative behavior were provided. This process of reinforcing alternative behavior during extinction is known as Counter-conditioning.

A more recent experimental examination of the role of a reinforced alternative response during extinction indicates, however, that the increased response suppression may be sonewhat 
transitory (Leitenberg, Rawson, \& Bath, 1970). These workers observed that as long as reinforcement for an alternative response vas maintained, suppression of the original response appeared to be more rapid and complete, but when such reinforcement of alterna-tive behavior was discontinued, the original response was resumed. The alternative response in this situation was a competing behavior of a similar topography or response class as the original response. It is this type of Counter-conditioning, that having a similar topography, which has been used almost exclusively in the area of response elimination, although Leitenberg et. al. (1970) suggested that Counter-conditioning as an applied technique may more profitably use a response of a completely different topography.

Facilitation of response elimination can also be achieved with another procedure, Differential Reinforcement of Other Behavior (DRO). In this procedure the organism is usually rewarded for not making a specific response for a specified period of time (Grant, 1964, Uhl \& Garcia, 1969). Technically in DRO the reinforced operant class includes all topographies except the one to be eliminated.

Another term often used to describe this procedure is Omission Training. The term Omission Training emphasizes the specific response and reinforcing contingencies involved (i. e. the subject has to omit a particular response to get reinforced) while Differen- 
tial Reinforcement of Other Behavior emphasizes these contingencies and also an explanation (i. e. all other behavior is being reinforced) for the response elimination effect (Johnson, McGlynn \& Topping, 1973). This author prefers the use of the latter term, which offers a better description of the "learning not to respond" procedure.

A problem emerges when one attempts to determine the "best" method of producing response elimination without the use of punishment. As the literature stands, there is no "best" method. Certain criteria of response elimination must be considered with whichever response elimination procedure one chooses. Two criteria continually emerge as being of primary coilcern. The first is that the procedure be relatively efficient, that is, it must serve to eliminate the response within a reasonable amount of time. The second is that the procedure should produce durable elimination effects, i. e., its effects should be relatively long-lasting. No one procedure at this time is clearly superior because these procedures have not been directly compared in a single study.

X,eitenberg, Rawson, \& Bath (1970) and Mulick (1973) attempted to compare the extinction procedure to counter-conditioning by reinforcing a competing (but similar) response as the original response was extinguished. Leitenberg et. al. (1970) revealed, how ever, that when reinforcement for the competing behavior was withdrawn, rats resumed their original behavior and there were no 
overall savings in total number of responses to extinction.

In a study by Enkema, Slavin, Spaeth, and Neuringer (1972) a very similar result was obtained. These workers provided free food during extinction of a key pecking response in pigeons. Then the free food, and thus the reinforcement for the alternative response of pecking at the grain in a food cup was removed. Key pecking responses thereafter resumed to the degree that the same total number of responses in extinction were emitted as by control subjects that never experienced the free food.

Thus when a response chosen to be counter-conditioned was of the same or similar response class as the original response, no overall savings in total number of responses to extinction has been observed. In fact, Leitenberg et. al. (1970) and Enkema et. al (1972) reported a pronounced "rebound effect" where the original response returned at a rate that may even be higher than its original rate of emission. This high rate of responding occured ever when no reinforcement was given. Gradually the responding decreased and thereafter followed the traaitional course of extinction. It was this initial high rate of responding after extinction of the counter-conditioned response, however, that resulted in the lack of overall savings in total number of responses to extinction.

Leitenberg, Rawson, and Mulick (1974) conducted a series of foun critical experinents that examined the course of extinction 
of one behavior as a function of the presence and subsequent $a b-$ sence of reinforcement for some alternative behavior.

Experiment I in this series revealed that when reinforcement for alternative behavior was discontinued, both a lick alternative response group (Counter-conditioning of a Different Response) and a bar-press alternative response group (Counter-conditioning of a Similar Response) of rats resumed the original response to such an extent that overall, there was no significant difference in total number of responses made by the two groups relative to each other, or to a control group that was never reinforced for alternative behavior. This experiment was carried out in a discrimination format, where certain periods of time signalled non-reinforcement. The non-reinforcernent periods (S periods) were used to evaluate the comparative efficiency of the two response elimination techniques. The rats in the two l'esponse elimination conditions did not differ in the total number of $S$ responses made, nor did they differ from control animals that were never reinforced for alternative behavior during these periods.

When used in a simple extinction procedure rather than a discrimination format different $r$ esults are obtained. Leitenberg et. al. (1973) note that curing the actual Counter-conditioning phase, temporary reinforcement of alternative behavior can lead to a significant savings in number of original responses made in that 
phase alone. This savings is considerably more than in the context of $S$ periods in discrimination learning. In the actual Counterconditioning phase, where reinforcement was provided for the alternative behavior, the Counter-conditioning of a different response group made fewer original responses than the Counter-conditioning of a similar response group.

Experiment II revealed that when frequency of reinforcement was kept constant, no difference between subjects on yoked variable interval and fixed ratio schedules of reinforcement for alternative behavior was noted. Thus the prior reinforced alternative response experience, whether on a FR or VI schedule of reinforcement, did not lead to a significant net reduction in number of original responses (again measured in $S$ periods).

Experiment III varied the frequency of reinforcement for alternative behavior during extinction. Unlike Experiments I and II, this experiment examined the role of reinforcement of aiternative behavior during simple extinction, rather than during $S$ periods in discrimination learning. Also pigeons rather than rats were used. Results showed that low frequency of reinforcement for alternative behavior (resulting 'from VI 4 minute schedule of reinforcement) produced no significant suppression of the original Key pecking response in Phase II (when alternative behavior was being reinforced), and did not result in a significant resumption of responding 
in Phase III, when the alternate key was no longer reinforced. High density of reinforcement (resulting from VI 30 second schedule) increased the suppressive effects of extinction, however.

Experiment IV, like Experiment III, was conducted in the context of a simple extinction paradigm to determine the effect of varying the length of time that reinforcement for alternative behavior was maintained during extinction in rats. When reinforcement for alternative behavior was maintained for a relatively long period (27 days) subsequent recovery of the original response programmed for extinction was less than usual. Here a substantial savings in total number of extinction responses was observed.

From the work of Leitenberg et. al. $(1974)$ it appears that temporary reinforcement for an alternative behavior, when used in a simple extinction procedure, may lead to significant savings in total number of original responses made during the reinforced alternative phase (but not overall). This does not occur, however, in the context of a discrimination learning paradigm, where extinction responses are measured during $S$ periods. These differences observed in number of original responses probably relate to the fact that in the discrimination paradigm the original response continued to be reinforced during $\mathrm{S}^{\mathrm{D}}$ periods throughout Phases II and IIL Leitenberg et. a1. (1.974) conclude that the original response remained prepotent, and due to a generalization process, might 
have caused the original response to recover more in $S$ than in extinction in Phase $\mathrm{III}$

Thus one observes two distinct Counter-conditioning procedures being employed. The first, Counter-Conditioning of a similar response, uses a competing response of an identical or very similar topography to the original response. When this procedure is used, either in a discrimination format or sinple extinction format, no overall savings in total number of responses to extinction occurs. Its effect resemble a type of response suppression similar to punishment produced response suppression (Boe \& Church, 1967) rather than true response elimination.

The second procedure, Counter-conditioning of a response with a different topography, uses a competing response with a different topography than the original response. Here the topography of the alternative response may be of some importance during the phase when reinforcement is provided. In Leitenberg \& Rawson's 1973 study, the lick alternative response group made fewer extinction responses during the treatment phase than did the bar press alternative response group. When reinforcement for alternative behavior was discontinued, both groups resumed the original response to such an extent that overall there was no significant difference in the total rumber of extinction responses made by the two groups relative to each other, or to an extinction controi group 
that was never reinforced for alternative behavior (Leitenberg \& Rawson, 1973).

Within both paradigms, frequency of reinforcement is clearly a major variable. High frequency of reinforcement for alternative behavior increased the suppressive effects of Counter-conditioning while low frequency of reinforcement did not. The length of time that reinforcement for alternative behavior is maintained is also important in producing durable suppression.

Either Counter-conditioning of a Similar Response or Counterconditioning of a Different Response show early efficiency as means of resporise reduction; both serve to suppress the original response at an early stage. However, in terms of overali efficiency, their effects are no more durable than those of traditional extinction; the original response returns once reinforcement for these alternative behaviors is withdrawn (the rebound effect).

The literature concerning the Differential Reinforcement of Other Behavior procedure shows that it is often less efficient than direct Counter-conditioning, but is relatively more durable. Often Differential Reinforcement of Other Behavior emerges as being even less efficient than traditional extinction training, in that the target response is not suppressed as quickly. In their comparison of Extinction with Differential Reinforcement of Other Behavior, Uhl \& Garcia (1969) reported that extinction training alone provided 
a more rapid ressation of responding than Differential Reinforcement procedure provided a much greater degree of durability of response elimination, measured in terms of difficulty in reconditioning the original response.

Uhl \& Garcia (1969) conducted two experiments that compared the efficiency and durability of elimination of a free operant using the Differential Reinforcement of Other Behavior and Extinction Training procedures with rats. The first experiment revealed a more rapid response elimination with Extinction Training than with Differential Reinforcement of Other Behavior, in terms of number of responses made in each condition on the first day of complete extinction; but a greater degree of durability of response elimination with Differential Reinforcement of Other Behavior in terms of number of responses made in a reconditioning session, where the original response was reinstated on the original contingencies.

Uhl \& Garcia (1969) in Experiment I irvestigated the temporal parameters thought to operate in the Differential Reinforcement of Other Behavior procedure to specify the contingencies between the subjects benavior and the reinforcement. The first of these parameters, the response-reinforcement interval $\left(R-S^{R}\right)$, sets the time that the reinforcement is postponed after emission of the last response. The second, the reinforcement-reinforcement interval $\left(S^{R}-S R\right)$, sets the time between reinforcements if no response 
intervenes. Experiment I the'efore varied these intervals in a $3 \times 3$ factorial design, and compared the effects of the procedures to those of control subjects, rats which received traditional $\mathrm{Ex}$ tinction Training.

Subjects underwent one day of bar-press shaping, and four days of VI-30 second reinforcement training. The Differential Reinforcement of Other Behavior or Extinction Training response elimination procedure was run for three testing days following this VI training. A Differential Reinforcement of Other Behavior subject received reinforcement according to the $\mathrm{R}-\mathrm{S}^{\mathrm{R}}$ and $\mathrm{S}_{-} \mathrm{SF}$ time intervals of the group it had been assigned to $(10-, 30-$; or 90-seconds). On day four all subjects were placed on extinction to compare the effectiveness of the preceding response elimination procedure. On day five all subjects were reconditioned on the VI-30 second schedule for the original bar-press. The major results showed that response elimination was more rapid with shorter $S^{R}-S R$ intervals and shorter $R-S^{R}$ intervals. A comparison of Differential Reinforcement of Other Behavior vs. Extinction Training effectiveness in response elimination was made by inciłding Differential Reinforcement vs. Extinction Training as a variable in this study. There was considerably more responding on the first day of testing with Differential Reinforcement of Other Benavinr compared with Extinction Training, and this difference 
diminished appreciably on the second and third days of testing. Thus Differential Reinforcement of Other Behavior proved to be Jess efficient than Extinction Training in that more responses were observed under the Differential Reinforcement condition initially. An examination of the retraining session, however, revealed that significantly more original responses were made by the Extinction Training group once reinforcement was reinstated, a demonstration of the fact that Differential Reinforcement of Other Behavior is a more durable means of response elimination. The explanation offered for the less efficient response elimination by Differential Reinforcement of Other Behavior involved the dis.. criminative reinforcement hypothesis (Grant, 1964). Uhl \& Garcia (1969) suggest that because in Differential Reinforcement of Other Behavior the stimulus of the reinforcer exerts a certain amount of discriminative control over responding, greater persistence of responding on the original lever compared to extinction is observed. In this type of explanation, the reinforcer $\left({ }^{2} R_{=f o o d}\right)$ is thought to act as ail $\mathrm{SD}$ for response resumption, and consequently Differential Reinfcrcement of Other Behavior resulted in less immediate response reduction than Extinction Training.

Experiment II in thl \& Garcia's (1969) study specifically investigatcd this hypothesis, i. ${ }_{-}$, that the discriminative stimulus effect of reinforcement was responsible for tire less efficient 
response elimination with Differential Reinforcement of Other Behavior, as well as the greater durability of Differential Rainforcement effects in Experiment I. The results of Experiment II clearly supported this sypothesis. In Experiment II all subjects were trained exactly as in Experiment I, except for the three days in which testing was conducted for Differential Reinforcement vs. Extinction Training response elimination effects. The $S R-S R$ and $\mathrm{R}-\mathrm{SR}$ intervals were 10 and 30 seconds respectively. Whenever cessation of responding permitted either the $R-S R$ or the $S^{R}-S R$ clock to time out, a thirty-second "Time Out" period began for both Differential Reinforcement and Extinction Training subjects. The lever was retracted, and all lights were turned out during the Time Out. In Condition A, only Differential Keinforcement of Other Behavior Subjects received $\mathrm{S}^{\mathrm{R}}$ when a clock timed out. In Condition $B$, Differential Reinforcement subjects received $S^{R}$ at the beginning of the Time out and in the last three seconds of Time Out, and Extinction Training subjects received $S^{R}$ only at the end of the Time Out. Conditions $\dot{A}$ and B were administered to all subjects in a counter-balanced order. Thus in Condition A discrimination was sliminated for the DRO Group, while Condition B equalized discrimination for both DFO and Extinrtion Groups.

Following the first three days of response elimination testing, one hour sessions of simple extinction, noncontingent VI $30-$ 
second reinforcement and contingent VI 30-second reiniorcement were run on successive days. Four additional days of retraining on contingent VI 30-second schedule followed. Next all subjects were retested in Differential Reinforcement of Other Behavior and Extinction Training for three days under the opposite condition from that which they had experienced on the first three days of Differential Reinforcement vs. Extinction Training testing. The experiment ended with successive daily one-hour sessions of simple extinction.

The main results were consistent with Un1 \& Garcia's expectation that differences in response-elimination efficiency between Differential Reinforcement of Other Behavior and Extinction Training would be substanitially reduced if the discriminative effect of $S^{R}$ in Differential Reinforcement were minimized by a Time Out procedure as in Condition $\mathrm{A}$, or if the discriminative effect of SR were applied to both Differential Reinforcement of Other Behavior and Extinction Training as in Condition B. Between these conditions, no significant differences were found in terms of number of original responses made in the first three days of response elimination. In this experiment, as in Experiment I, however, little response resumption occurred among Differential Reinforcement of Other Behavior subjects in subsequent simple extinction testing, although initially there was more respuriding after 
Differential Reinforcement than after Extinction Training.

The effectiveness of DRO was further supported by UhI and Sherman (1971), who compared combinations of Differential Reinforcement of Other Behavior, punishment, and extinction methods in response elimination in rats. Using a lever press situation and sucrose-water reinforcement, response elimination was more rapid when punishment was used in combination with Differential Reinforcement or Extinction Training, in comparison with either Extinction Training or Differential Reinforcement alone, in terms of number of responses made to criterion.

The durability of response elimination, however, was greater when Differential Reinforcement of Other Behavior was used alone in comparison with Extinction alone or combinations of punishment and Extinction or punishment and Differential Reinforcement of Other Behavior. These results amplify those of Uhl \& Garcia (1969) demonstrating the efficacy of Differential Reinforcement of Other Behavior as a response elimination procedure, especially in terms of the relativaly greater durability of Differential Reinforcement effects in comparison with other methods of response reduction in terms of number of original responses made during complete extinction.

In another study evaluating Differsintial Reinforcement of Other Behavior as a response elimination procedure, Zeiler (1971) 
showed that food presentation dependent upon not responding reduced the pecking rate in pigeons faster than extinction alone. He used the traditional Omission Training, or Differential Reinforcement of Other Behavior technique, in which not making a certain specified response for a period of time brought reinforcement. Responding produced food according to an FR schedule while the prevailing key color alternated between red and blue. Stimulus durations wele varied until a period was found that maintained equal rates of responding in the presence of both colors. Then food presentation was discontinued in the presence of one stimulus and made dependent upon not responding in the presence of the other. Food presentation dependent upon not responding reduced the rate of responding faster than did extinction alone.

In a discrimination format, (in contrast to the findings of Uhl \& Garcia, 1969) Differential Reinforcement of Other Behavior appears to be a more efficient method of response elimination than traditional extinction. This finding was also supported in a study using human subjects, where Extinction Training, Differential Reinforcement of Other Behavior, Response Cost, and Differential Reinforcement plus Response Cosi were compared (Johnson, McGlyni, and Topping, 1973). Subjects were trained on a VR schedule and then shifted to one of the four response elimination procedures, in which the original task (accumulating 
points on a zounter by reacting to a light stimulus on a telegraph key) was extinguished. Again, results indicated that the Differential Reinforcement of Other Eehavior procedure eliminated responding significantly faster than did Extinction Training, although not as fast as Response Cost, (a form of punishment).

Omission Training or Differential Reinforcenıent of Other Behavior at times may be less efficient than Extinction Training and at times may reduce responding faster than Extinction Training. As a treatment, however, Differential Reinforcement of Other Behavior proves to be more durable than the other response reduction techniques, thus meeting an important criterion for a good response elimination technique. It appears that the subject learns not to respond on the original manipulandum, rather thian merely having his responding suppressed as in the Counter-conditioning procedures.

The present study represented a direct comparison of four response-elimination procedures. Except for Experiment I in Leitenberg et. \pm (1974), the introduction of an incompatible response with a distinctly different topography has been absent from the literature. In addition, little work has been reported that compared the effectiveness of Differential Reinforcement of Other Behavior and Extinction Training with a Counter-conditioning procedure in which the original response is replaced with 
another of either a similar or different topography. This study represented a direct comparison of these four response elimination procedures with the objective of directly determining which is the most effective as a method of response elimination.

In the current study a direct comparison of the foum response elimination techniques in terms of efficiency and durability of response elimination was undertaken. This study was, in part, a replication of Leitenberg's procedures using a similar alternative response (a lever press) and a response with a markedly different topography (a pole push). This study did not, however, employ a discrimination format. Rather both procedures were carried out in a direct excinction paradigm, with no $\mathrm{S}^{\mathrm{D}}$ or $\mathrm{S}$ periods presert. Thirty-two rats received VI 30-second training for food reinforcement and then were shifted to one of the following response elimination procedures in the Treatment Phase: Extinc.tion Training (ET); Differential Reinforcement of Other Behavior (DRO); Counter-conditioning of a Different Response $\left(\mathrm{CC}^{\mathrm{D}}\right)$; and Counter-conditioning of a Similar Response (CCS). The Test Phase consisted of withdrawal of reiniorcement in all groups, and the final Reconditioning Phase consisted of retraining the original response on the original VI 30-second schedule for one session.

Efficiency of the tecinique was determined by number of 
responses on the original lever during the Treatment Phase. Relative durability of the procedure was determined by the number of lever - presses on the original lever during the Test Plase (complete extinction) and the Reconditioning phase. The relative durability is considered the primary criterion for a "good" response elimination procedure.

The number of responses emitted in the reconditioning session was considered a critical measure of overall utility of the procedure, because applied behavioral programmers employing these techniques must be aware of how resistent the response is (after it has been elirninated with one of the response elinination techniques) to relearning when the reinforcement contingencies are reinstated, or made available again. To date, this measure has not been examined for all the response elimination procedures discussed above. 


\section{METHOD}

Subjects

The subjects were 32 naive male albino rats weighing 240 340 gms., obtained from the Charles Rivers Breeding Laboratories. The aninuls ranged from 90-.120 days old at the start of trainung.

Apparatus

The exporiment was conducted in three sound-attcnuating chamber's consiructod using surplus whole blood containers. Each chamber was furnished with a $25.4 \mathrm{~cm}$. $\times 22.86 \mathrm{~cm}$. $\mathrm{x} 19.05 \mathrm{~cm}$. standard lever box and pellet feeder. Each box was illuminated by a 15 watt overhead light and ventilated by a silent exhaust fan.

Each lever box contained three manipulanda at all times: two standard Scientific Prototype rat levers (one mounted on each side of the food cup) and one omnidirectional $16.5 \mathrm{~cm}$. long pole, centered and suspended from the top of the lever box $12.5 \mathrm{~cm}$. away from the wall with the levers and food cup. Electro-machanical programming equipment was localed in an adjacent room. Counters registered number cf respenses made oll each manipulandum, along with number of reinforcements delivered. Reinforcements consiated of single $45 \mathrm{mg}$. Noyes food pellets.

\section{Drocedure}

Each subject was randomly assigned to one of four groups 
$(n=8)$. All subjects were shaped to make the original response on one of the levers (Lever $\mathrm{A}=$ original lever). The side of the original lever was varied for different replications. Following preliminary training daily sessions were always one hour long. The Training Phase consisted of five days on the VI 30-second schedule for the original Lever A responding. In the five days of the Treatment Phase the original lever was extinguished and the four different response-elimination procedures were introduced. Group ET was giveri no further reinforcenent on any manipulandum. Group DRO was reinforced for not pressing Lever $A$ with $S^{R}-S^{R}$ intervals and $R-S^{R}$ intervals of 20 -seconds. If subjests in this group made a response on the original lever, reinforcement was postponed for 20 seconds. Group $\mathrm{CC}^{\mathrm{D}}$ was reinforced on a $\mathrm{FR}$ schedule for the pole-push response. The schedule was built up to FR 10 over the first 30 minutes of Treatment Session I, and maintained at FR 10 thereafter. Group $\mathrm{CC}^{\mathrm{S}}$ was reinforced for pressing the alternate Lever (Lever B) on an FR 10 schedule built up the same way as the $\mathrm{CC}^{\mathrm{D}}$ group).

During the five days of the Test Phase, all reirforcement was discontinued and the number of responses on each manipulandum was recorded.

Two days after the last Test session all subjects were reconditioned on the original lever on the VI 30-second schedule 
$-23-$

for one hour. 


\section{RESULTS}

The major focus of this study was on the number of Iever A responses during the Treatment, Test and Reconditioning Phases of the Experiment. Also examined were responses on the alternate manipulanda, Lever B and Pole, for each phase of the experiment. To determine if all subjects were at the same level of responding on the original lever at the end of the Training Phase, number of responses made on this manipulandum over the five training sessions was examined. The frequency of Lever A responding during VI 30 second Training Phase is stimmarized in Figure 1 and Table 1 for each group over the five training sessions. 


\section{TABLE 1}

Mean Number and Standard Deviations of Lever

A Responses for each Group over five Training Sessions

Session

\begin{tabular}{|c|c|c|c|c|c|c|}
\hline Group & & 1 & 2 & 3 & 4 & 5 \\
\hline ET & $\mathrm{M}$ & 104.00 & 523.75 & 640.12 & 724.12 & 1146.00 \\
\hline & S. D. & 53.10 & 292.57 & 145.51 & 230.91 & 460.14 \\
\hline DRO & $M$ & 132.37 & 274.25 & 621.12 & 667.25 & 784.00 \\
\hline & S. D. & 132.36 & 200.89 & 328.35 & 412.98 & 483.12 \\
\hline $\mathrm{CC}^{\mathrm{D}}$ & $M$ & 99.00 & 370.38 & 513,25 & 631.50 & 710.25 \\
\hline & S. D. & 52.25 & 271. 31 & 260.50 & 414.43 & 344.42 \\
\hline $\mathrm{CC}^{\mathrm{S}}$ & $M$ & 128.12 & 428.75 & 625.75 & 699.50 & 902.25 \\
\hline & S. D. & 108 & 234.83 & 404.91 & 426.82 & 564.53 \\
\hline
\end{tabular}


Fig. 1. Mean Number of Lever A Responses During Each Training Session. 




TRAINING TRIALS 
Figure 1 shows that each group acquirea the original Lever A response at approximately the same rate over the five training sessions. Means and standard deviations for this Phase are presented in Table 1. Variability was pronounced in all groups for Lever A responding during this phase, as evidenced by the large standard deviations. However, an $F_{\text {MAX-Test failed to re- }}$ veal significant heterogeneity of variance. Since the shape of the distributions was very similar, the two-factor Analysis of Variance was run to determine if there was any statistically significant difference in number of responses pricr to any differential treatment. The Analysis of Variance was performed on the mean number of responses emitted on Lever A for each group over the five training sessions. The ANOVA (the summary table of which is Iocated in Appendix 1) indicated no significant group differences in terms of number of bar-presses made on the original manipulandum during the Training Phase $(F<1.00)$. A sirnificant change over trials for all groups was obtained $\left(F=30 . \hat{0}^{1}\right.$, d. f. 4/112; $\mathrm{p}<.001)$ and no significant trial $\mathrm{x}$ condition interaction was obtained $(F<1.00)$.

To assess the relative efficiency of the resporse elimination procedures, mean number of responses on each group on Lever A during each treatment session, where each group received 
Fig. 2. Mazin Number of Lever A Responses Luring Eoh Treatment Sfssion 


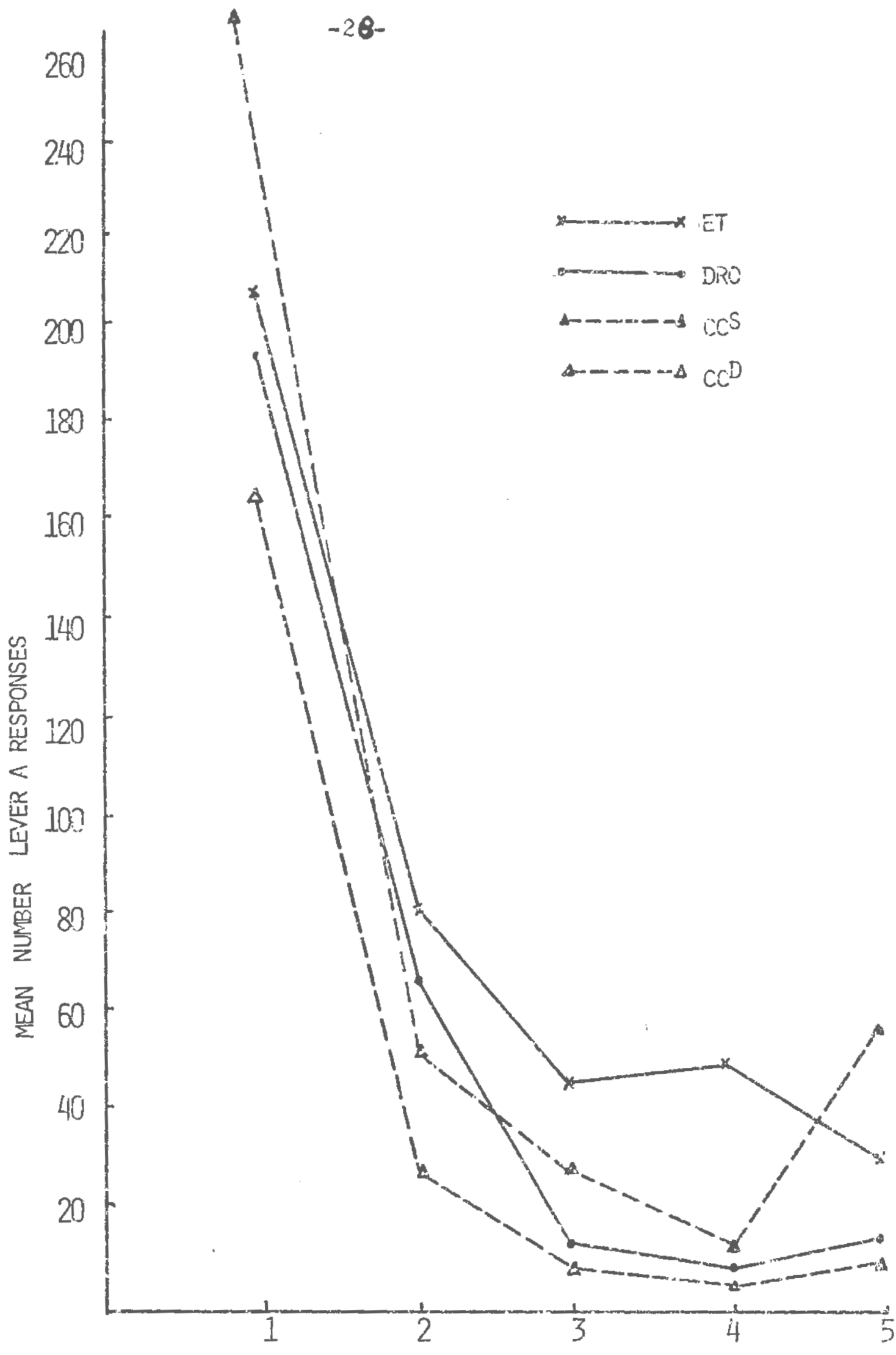

TREATIETT TRIALO 
a different response elimination procedure were compared. Table 2 and Figure 2 present the mean number of Lever A responses during each of the five treatment sessions.

\section{TABLE 2}

Mean Number and Standard Deviations for each Group over five Treatment Sessions

Sessions

\begin{tabular}{|c|c|c|c|c|c|c|}
\hline \multirow{3}{*}{$\begin{array}{r}\text { Group } \\
\text { E'T }\end{array}$} & \multicolumn{2}{|r|}{1} & \multirow{3}{*}{$\begin{array}{c}2 \\
80.87 \\
64.13\end{array}$} & \multirow{3}{*}{$\begin{array}{c}3 \\
44.25 \\
40.73\end{array}$} & \multirow{3}{*}{$\begin{array}{l}4 \\
48.12 \\
62.86\end{array}$} & \multirow{3}{*}{$\begin{array}{l}5 \\
33.62 \\
33.97\end{array}$} \\
\hline & $\mathrm{M}$ & 308.50 & & & & \\
\hline & S. D. & 187.03 & & & & \\
\hline \multirow[t]{2}{*}{ DRO } & $\mathrm{M}$ & 189.56 & 63.75 & 15.50 & 11.50 & 19.50 \\
\hline & S. D. & 199.94 & 94.91 & 11.78 & 3.08 & 20.99 \\
\hline \multirow[t]{2}{*}{$\mathrm{CC}^{\mathrm{D}}$} & M & 163.12 & 28.75 & 9.12 & 4,50 & 10.75 \\
\hline & S. D. & 68.12 & 43.49 & 11. 91 & 4. 43 & 9.06 \\
\hline \multirow[t]{2}{*}{$\mathrm{CC}^{\mathrm{S}}$} & M & 270.87 & 48.75 & 27.00 & 16. 50 & 60.87 \\
\hline & S. D. & 225.47 & 68.62 & 43.81 & 31.20 & 120.64 \\
\hline
\end{tabular}

Figure 2 shows the effectiveness of each procedure nqu the five treatment sessions. Initially, the $\mathrm{CC}^{\mathrm{S}}$ Group made the most Lever A pusses, bat decreased at a faster rate than the other groups. $\mathrm{CC}^{D}$ Group made the fewest original Lever A presses over the enixe Treatratnt phase.

From an uxanlidation of the Treatment phase it would appear that the $C^{b}$ Croup was slightly more efficient than the others in 
terms of eliminating the original response.

An examination of the data during the Treatment Phase revealed pronounced heterogeneity of variance present between each of the groups ( $\left.{ }^{\mathrm{F}} \mathrm{MAX}=4.986, \mathrm{p}<.05\right)$ during this phase. (See Appendix B, Table 1.) A Kruskal-Wallis analysis of variance by ranks, according to Hays (1963) was therefore performed on mean number of responses for each group during the Treatment Phase. The Kruskal-Wallis test was chosen, because compared with the most powerful parametric test, the $\mathrm{F}$ Test, under conditions where the assumptions associated with the statistical model of the $F$ Test are met, the Kruskal-Wallis test has asymptotic efficiency of 95.5 per cent (Andrews, 1954). When compared to other non-parametric tests, the Kruskal-Wallis is found to be more efficient because it uses more information in the observations. It converts the scores to ranks, rather than simply pluses or minuses, as the median test does. Overall, the Kruskall-Wallis test preserves the magnitude of the scores more fully, and because of this, is more sensitive to differences among the k-samples of scores (Seigal, 1956). 
Fig. 3. Mean Number of Lever A Responses during each Test Day. 


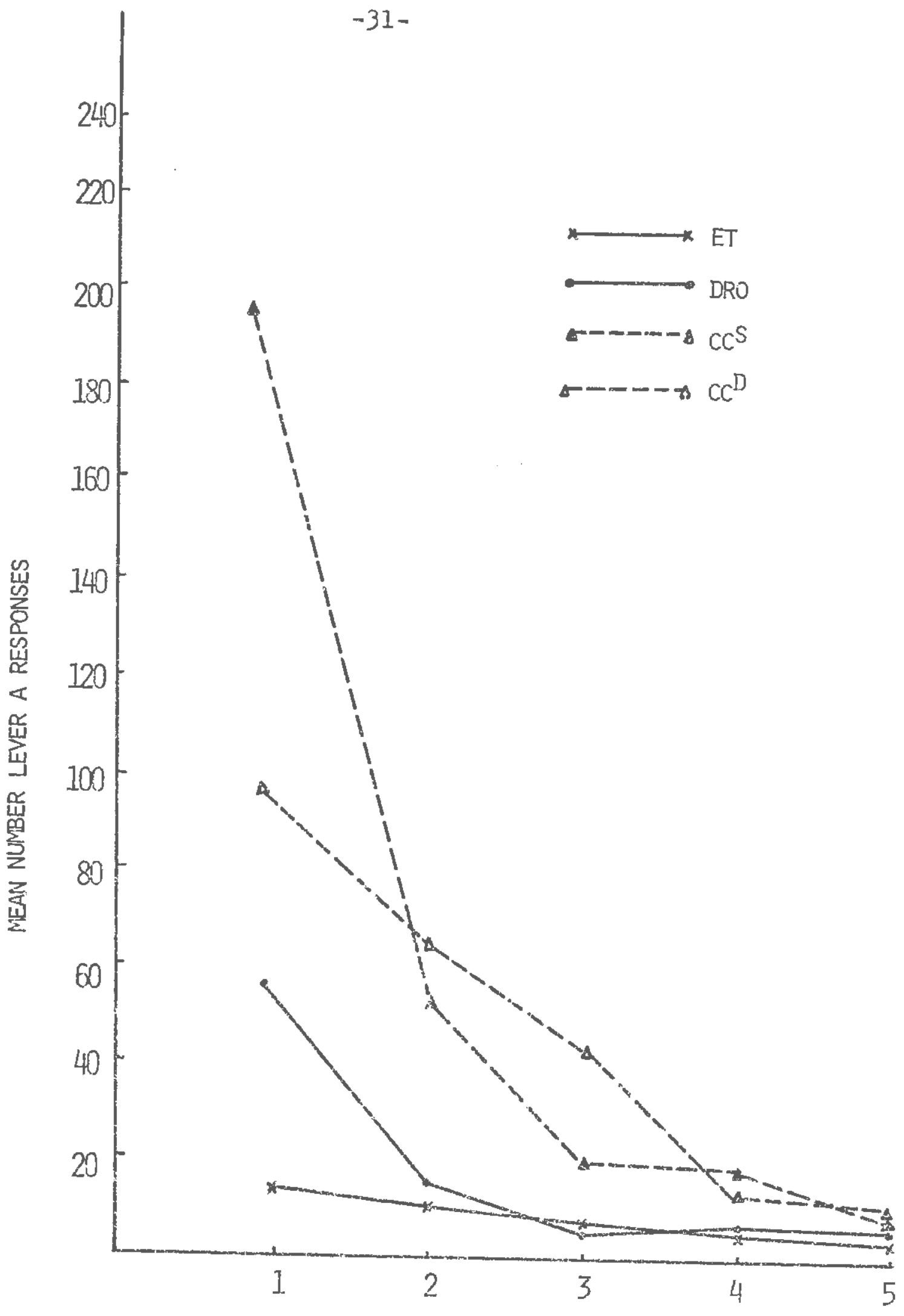

TEST TRIALS 
No significant difference was obtained $(H=1.139)$ between mean number of Lever A responses between groups during this phase.

In the Test Phase, all reinforcement for alternative behavior was discontinued. The number of responses emitted during this phase of the Experiment gives an indication of the durability of the response elimination procedure employed. As shown in Figure 3 and Table 3 , the two Counter-conditioning groups resumed responding on the original lever at a high rate, with $\mathrm{CC}^{\mathrm{S}}$ Group making the most responses initially. 


\section{TABI,E 3}

Mean Number and Erandird Deriations for

Each Group over Five Test

Sessions

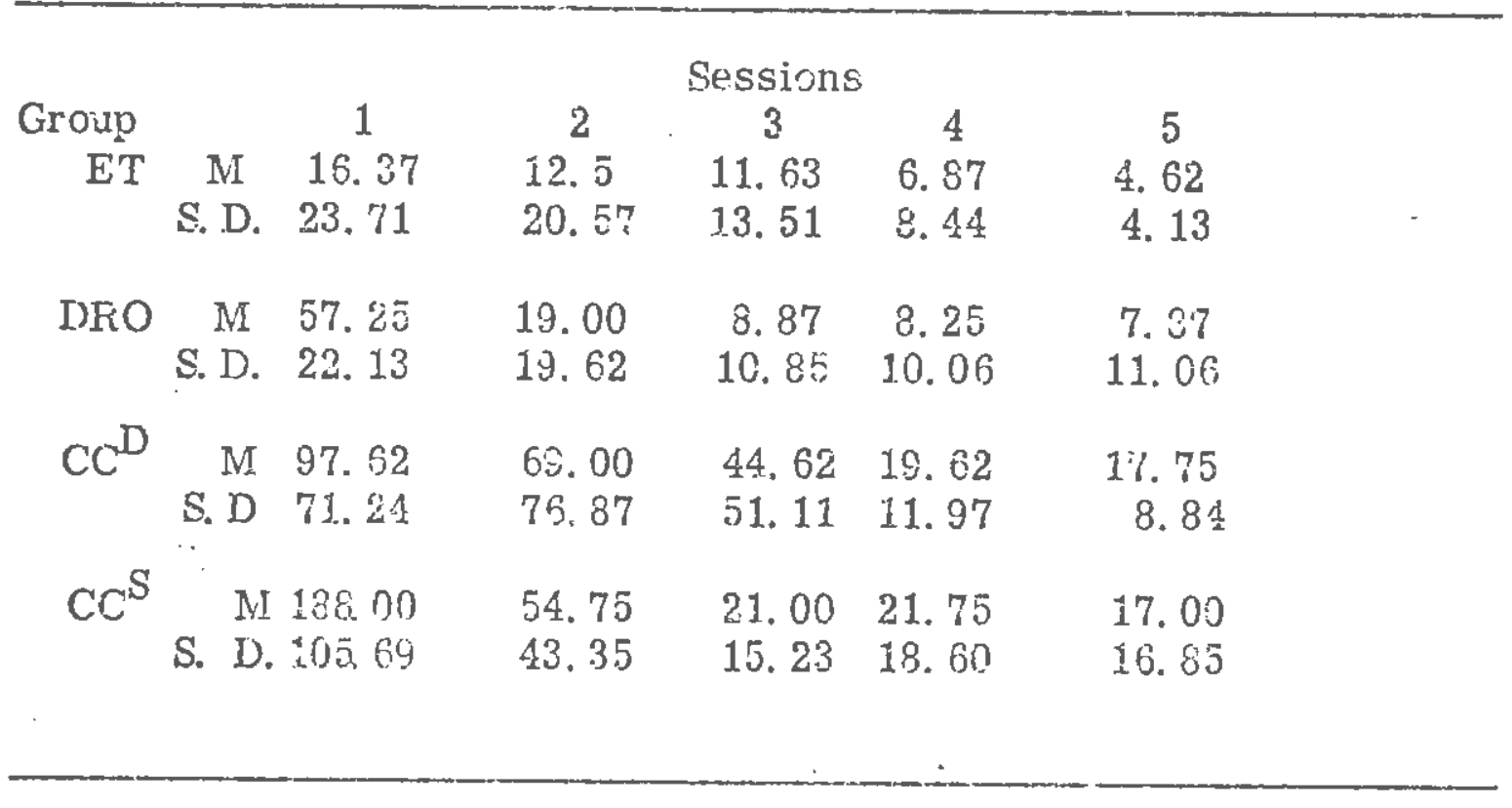

The $\mathrm{CC}^{\mathrm{D}}$ Group made the next nost original Lever A presses. while DRO and Er followed in rumber. Table 3 gives means and standard deviations for each group on each test session.

Responding on the iirst day of test phiase ranged from only 17 responses foi the ET Giolp to cren 180 responses for the $\mathrm{CC}^{\mathrm{S}}$ Group.

To assess the relative durability of each of the response elimination procciures, number of responses nade by each group on the criginal Iever 4 were compared during the Test Phase. Again, pronounced heterogeneity of variance between 
groups was evident ( $\left.{ }^{\mathrm{M}} \mathrm{MAX}=40.650, \mathrm{p}<.01\right)$. A Kruskal-Wallis analysis of variance by ranks revealed a significant difference between the four groups in terms of number of responses made on the original Lever A during the Test Phase ( $H=15.188, p<.001)$. Mann-Whitney U-Tests, the results of which are presented in Table 4, revealed that the only two groups that did not differ in total number of responses were $\mathrm{CC}^{\mathrm{D}}$ Group and $\mathrm{CC}^{\mathrm{S}}$ Group.

TABLE 4

Mann-Whitney U Tests:

Number of Lever A Presses in Test

\begin{tabular}{ccll} 
Group & DRO & $\mathrm{CC}^{\mathrm{D}}$ & $\mathrm{CC}^{\mathrm{S}}$ \\
$\mathrm{ET}$ & $\mathrm{U}=14 *$ & $\mathrm{U}=4 * *$ & $\mathrm{U}=4 * *$ \\
DRO & & $\mathrm{U}=12 *$ & $\mathrm{U}=8 * *$ \\
$\mathrm{CC}^{\mathrm{D}}$ & & $\mathrm{U}=25$ N. S. \\
& & \\
\hline$* \mathrm{p}<.05$ & & \\
\hline * $<.01$ & & \\
\hline
\end{tabular}

The ET Group made the fewest original Lever A presses in the Test Phase, followed by the DRO Group, followed by the $\mathrm{CC}^{\mathrm{D}}$ Group and the $\mathrm{CC}^{5}$ Group.

The most critical measure of durability of response elimination was made in the Reconciitioning Session. Table 5 presents Means and Standald Devialions for Eash Group during 
Fig. 4. Mean Number of Lever A Responses for each Group During Reconditioning 


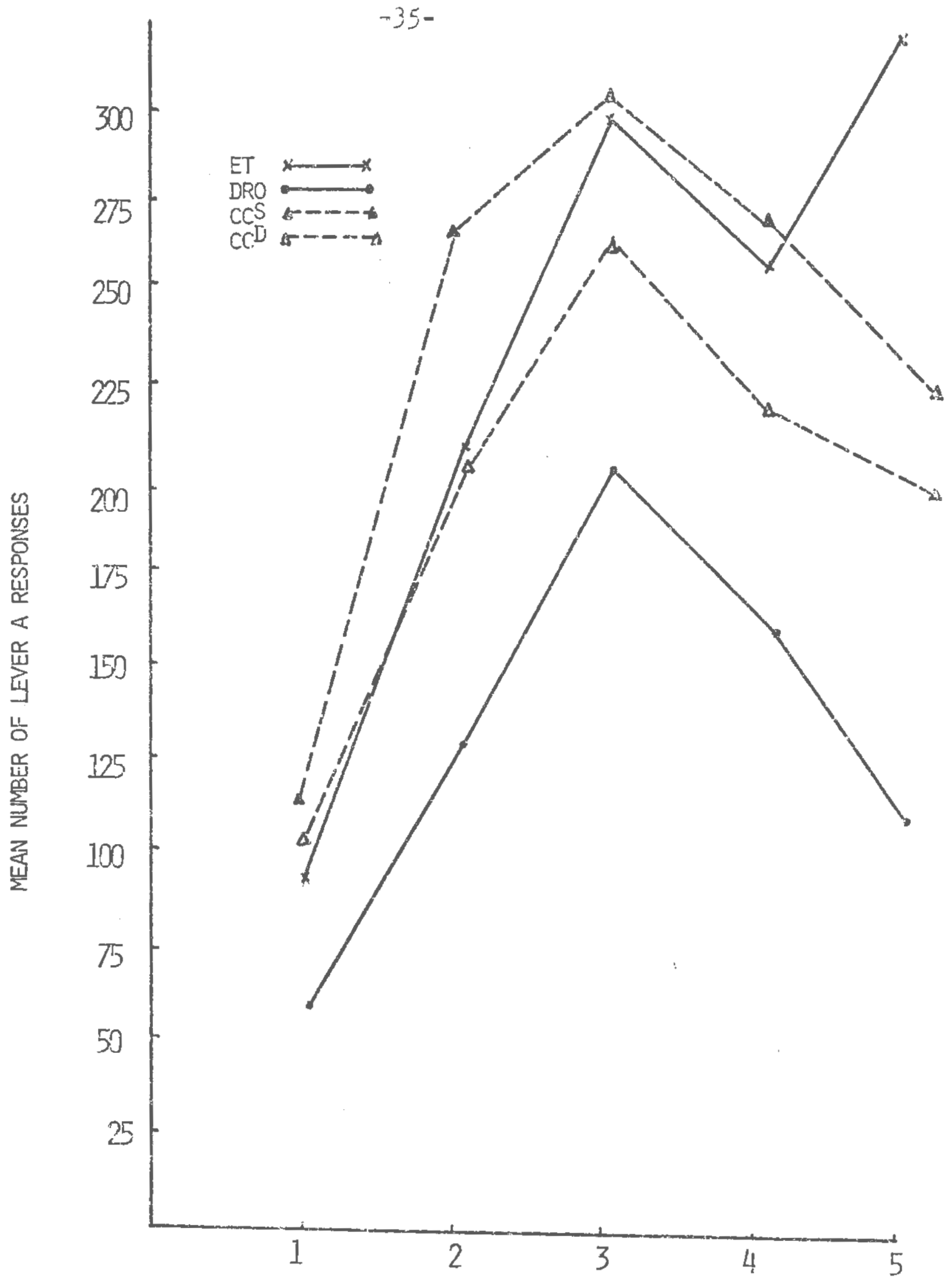

TWELVE MINUTE PERIODS 
the Reconditioning Session. During this 1 hour retraining session number of original Lever A responses were recorded at the end of every 12 minutes. These data are illustrated in Figure 4, which gives mean number of bar presses for each group during the five 12 minute periods.

\section{TABLE 5}

Mean Number and Standard Deviations for Lever A Presses in Reconditioning Session

Twelve Minute Periods

\begin{tabular}{rrrrrrr} 
Group & & 1 & 2 & 3 & 4 & 5 \\
ET & M & 89.50 & 206.25 & 272.10 & 245.50 & 283.10 \\
S. D. & 84.41 & 187.43 & 204.61 & 201.11 & 248.11 \\
DRO M & 66.75 & 126.88 & 180.63 & 146.50 & 112.63 \\
S. D. & 65.45 & 89.91 & 141.61 & 128.42 & 89.11 \\
CC & & & & & & \\
M & 100.25 & 198.30 & 251.50 & 200.50 & 172.75 \\
S. D. & 89.98 & 199.13 & 241.12 & 198.89 & 158.87 \\
CC S & & & & & \\
\multicolumn{2}{l}{ S. D. } & 113.00 & 262.30 & 277.60 & 241.10 & 193.50 \\
S. & 102.22 & 241.33 & 266.61 & 238.10 & 189.89
\end{tabular}


These data show that the DRO Group appears to be different from each of the other groups in terms of relearning the original Lever A response.

The DRO Group made the fewest responses on the original Lever A during the Reconditioning session. An examination of Figure 4 reveals a pronounced difference between the DRO Group and the other three groups. This difference, when examined over trials (12 minute segments) shows that during each 12 minute segment the DRO Group made the fewest original Lever A presses, even though during Training, Treatment and Test Phases this group was intermediate in terms of number of presses made during each session.

Because of the heterogeneity of variance present between groups in this 1 hour session $\left({ }^{\mathrm{F}} \mathrm{MAX}=2.835, \mathrm{p}<.05\right)$, the KruskalWallis analysis of variance by ranks was performed for total number of Lever A responses for each group during the 1 hour Reconditioning session. A significant difference was observed $(H=4.463, p .<.001)$. Table 6 illustrates the results of the Mann-Whitney U-Tests and shows that the DRO Group was significantly different from $C C^{D}$ and $C C^{S}$, but not from ET. 
TASEL 6

Mann Whitney U-Tests: Number

of Lever A Responses in Recondjtioning Session

$\begin{array}{cccc}\text { Group } & \text { DRO } & \mathrm{CC}^{\mathrm{D}} & \mathrm{CC}^{\mathrm{S}} \\ \text { ET } & \mathrm{U}=20 . \mathrm{N} . \mathrm{S} . & \mathrm{U}=27 \mathrm{~N} . \mathrm{S} . & \mathrm{U}=28 \quad \mathrm{~N} . \mathrm{S} . \\ \text { DRO } & & \mathrm{U}=16 * & \mathrm{U}=15 * \\ \mathrm{CC}^{\mathrm{D}} & & & \\ & & & \mathrm{U}=55 \mathrm{~N} \text {. S. }\end{array}$

$* \mathrm{p}<.05$

To compare the response elimination procedures in terms of overall efficiency, total number of responses made on Lever A in both Treatment and Test Phases combined werc examined. This analysis would indicate which response elimination procedure would yield the fewest original responses during the course of eliminating the behavior. Thus each group's totai Lever A responses were combined for the Treatment and Test Phases and compared. Mean Number of responses made overall in the Treatment and Test Phases combined for each group were ET:407.35, DKO: 401.00, $\mathrm{CC}^{\mathrm{D}}: 464.89$, and $\mathrm{CC}^{\mathrm{S}}: 725.50$.

An examination of the data in this comparison revealed a significant degree of variance $\left({ }^{F}\right.$ MAX $\left.=2.71 \mathrm{p}<.01\right)$ Therefore, a Kruskal-Wallis analysis of variance by ranks was performed and 
revealed a significant difierence betwcen the groups in total number of responses made during the Treatment and Test Phases combined $(\mathrm{H}=4.577, \mathrm{p} .<.01)$. Table 7 illustrates the results of the Mann-Whitney U-Tests, and demonstrates that ET and DRO differed from the $\mathrm{CC}^{\mathrm{S}}$ Group, which made the most lever A responses overall. The DRO Group made the fewest original responses overall, and ET made the second fewest. The $\mathrm{CC}^{\mathrm{D}}$ Group made almost an identical number of responses as the ET Group.

\section{TABLE 7}

Mann-Whitney U-Tests: Overall Number of Lever A Responses in Treatment and Test Combined

\begin{tabular}{|c|c|c|c|}
\hline Group & DRO & $\mathrm{CC}^{\mathrm{D}}$ & $\mathrm{CC}^{\mathrm{S}}$ \\
\hline $\mathrm{ET}$ & $U=23$ N. $S$. & $\mathrm{U}=28$ N. S. & $\mathrm{U}=18$ N. S. \\
\hline DRO & & $U=23 \quad$ N. S. & $\mathrm{U}=15^{*}$ \\
\hline $\mathrm{CC}^{\mathrm{D}}$ & & & $U=20 \quad \mathrm{~N} . \mathrm{S}$. \\
\hline
\end{tabular}

The number of responses made on the aiternate manipulanda during each of the phases of the experiment were also analyzed. 'These anlyses showed the degree to which each group was responding on ine other available, but not necessarily reinforced, raripulanda for each response elimination procedure. 
Fig. 5. Total Number of Lever B Responses During Each day of Training, Treatment, and Test phases 


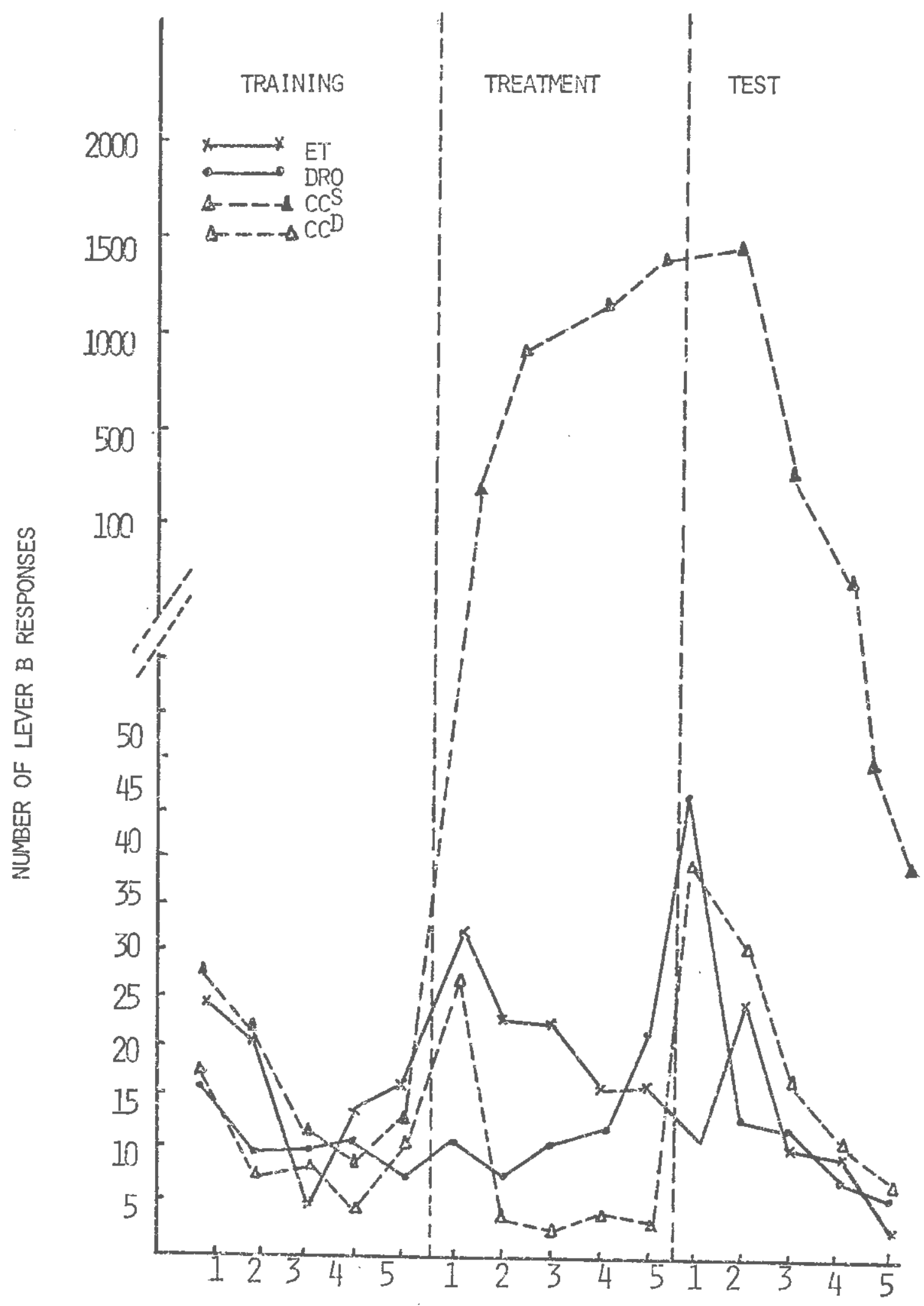

TRIALS 
Figure 5 shows number of alternate Lever B presses for each group over the ccurse of the experiment, while Table 8 gives means and standard deviations for each group during the sive Training Sessions.

\section{TABLE 8}

Mean Number of Lever B Responses and Standard Deviations for each Group over 5 Training Trials

\begin{tabular}{|c|c|c|c|c|c|}
\hline \multirow[b]{2}{*}{ Group } & \multicolumn{4}{|c|}{ Session } & \multirow[b]{2}{*}{5} \\
\hline & 1 & 2 & 3 & 4 & \\
\hline ET & $\begin{array}{r}\text { M } 24.15 \\
\text { S. D. } 23.13\end{array}$ & $\begin{array}{l}18.75 \\
22.14\end{array}$ & $\begin{array}{l}3.62 \\
7.15\end{array}$ & $\begin{array}{l}13.00 \\
22.74\end{array}$ & $\begin{array}{l}16.50 \\
28.72\end{array}$ \\
\hline DRO & $\begin{array}{r}\text { M } 15.25 \\
\text { S. D. } 14.30\end{array}$ & $\begin{array}{l}7.12 \\
6.46\end{array}$ & $\begin{array}{c}8.37 \\
10.98\end{array}$ & $\begin{array}{r}9.00 \\
13.41\end{array}$ & $\begin{array}{l}5.75 \\
8.64\end{array}$ \\
\hline $\mathrm{CC}^{\mathrm{D}}$ & $\begin{array}{r}\text { M } 16.25 \\
\text { S. D. } 14.98\end{array}$ & $\begin{array}{r}7.25 \\
10.89\end{array}$ & $\begin{array}{r}7.25 \\
11.31\end{array}$ & $\begin{array}{l}2.87 \\
4.45\end{array}$ & $\begin{array}{l}10.87 \\
16.04\end{array}$ \\
\hline $\mathrm{CC}^{\mathrm{S}}$ & $\begin{array}{r}\text { M } 28.37 \\
\text { S. D. } 16.78\end{array}$ & $\begin{array}{l}19.12 \\
15.80\end{array}$ & $\begin{array}{l}11.50 \\
12.86\end{array}$ & $\begin{array}{l}8.75 \\
12.37\end{array}$ & $\begin{array}{l}13.12 \\
16.56\end{array}$ \\
\hline
\end{tabular}

An examination of Figure 5 indicates that during the Training Phase no clear differences exist between the groups. For the $\mathrm{CC}^{\mathrm{S}}$ Group during the Treatment. Phase, however, the rate of pressing Lever $B$ and total number of Lever B responses was greatly different from the other groups that were not being reinforced for this alternate lever. ET and DRO remained at the same approximate frequency 
they were at during the Training Phase, where no reinforcement was given for any of the alternate manipulanda.

A test for amount of variability within each of the groups during the Training Phase yielded significant heterogeneity of variance $\left({ }^{\vec{k}} \mathrm{MAX}=3.93, \mathrm{p}<.05\right)$. A. Kruskal-Wallis analysis of variance by ranks yielded significant differences between groups during the Training Phase on Lever B responses $(H=4.711, p<001)$. The results of the Mann-Whitney U-Tests are presented in Table 9 and indicate that in the Training Phase the $\mathrm{CC}^{\mathrm{S}}$ Group made significantly more Lever B responses than both the DRO Group and the $\mathrm{CC}^{\mathrm{D}}$ Group. No other differences were observed.

TABLE 9

Mann-Whitney U-Tests: Number of Lever B Responses in Training Phase

\begin{tabular}{cccc}
\hline Group & DRO & $\mathrm{CC}^{\mathrm{D}}$ & $\mathrm{CC}^{\mathrm{S}}$ \\
ET & $\mathrm{U}=\mathbf{2 4}$ N. S. & $\mathrm{U}=\mathbf{2 2}$ N. S. & $\mathrm{U}=28$ N. S. \\
DRO & & $\mathrm{U}=\mathbf{2 5}$ N. S. & $\mathrm{U}=14^{*}$ \\
$\mathrm{CC}^{\mathrm{D}}$ & & & $\mathrm{U}=15^{*}$
\end{tabular}

$* p<.05$

An analysis of alternate Lever $B$ responding in the Treatment Phase indicated that $\mathrm{CC}^{\mathrm{S}}$ Group made more Lever $\mathrm{B}$ responses 
than any other group. This observation is clear from examining the Treatment portion of Figure 5. This analysis also yielded significant differences between the four groups $(H=20.73, p<.001)$ in terms total number of Lever $B$ responses in the Treatment Phase. Table 10 gives means and standard deviations for each group during the five treatment Sessions, while Table 11 presents the results of the Mann-Whitney U-Tests which show that during the Treatment Phase the $\mathrm{CC}^{\mathrm{S}}$ Group was significantly different from all the other groups, and that $\mathrm{CC}^{\mathrm{D}}$ Group differed from the ET Group. No other differences were obtained.

\section{TABLE 10}

Mean Number and Standard Deviations of Lever B Responses for Each Group Over Treatment Sessions

\begin{tabular}{|c|c|c|c|c|c|}
\hline \multicolumn{6}{|c|}{ Session } \\
\hline $\begin{array}{l}\text { Group } \\
\text { ET } \quad \text { M } \\
\text { S. D. }\end{array}$ & $\begin{array}{l}1 \\
32.21 \\
18.53\end{array}$ & $\begin{array}{l}2 \\
22.12 \\
27.13\end{array}$ & $\begin{array}{c}3 \\
21.62 \\
30.48\end{array}$ & $\begin{array}{c}4 \\
14.74 \\
17.61\end{array}$ & $\begin{array}{l}5 \\
14.75 \\
26.60\end{array}$ \\
\hline $\begin{array}{r}\text { DRO M } \\
\text { S. D. }\end{array}$ & $\begin{array}{l}9.38 \\
6.41\end{array}$ & $\begin{array}{r}7.87 \\
11.35\end{array}$ & $\begin{array}{r}9.00 \\
13.91\end{array}$ & $\begin{array}{r}9.87 \\
13.83\end{array}$ & $\begin{array}{l}22.00 \\
37.96\end{array}$ \\
\hline $\begin{array}{ll}\mathrm{CC}^{\mathrm{D}} & \mathrm{M} \\
& \text { S. } \mathrm{D} .\end{array}$ & $\begin{array}{l}25.75 \\
28.48\end{array}$ & $\begin{array}{l}3.87 \\
2.53\end{array}$ & $\begin{array}{c}1.37 \\
1.06\end{array}$ & $\begin{array}{l}1.25 \\
2.05\end{array}$ & $\begin{array}{l}1.75 \\
1.58\end{array}$ \\
\hline $\begin{array}{ll}\mathrm{CC}^{\mathrm{S}} & \mathrm{M} \\
& \text { S. D. }\end{array}$ & $\begin{array}{l}776.00 \\
392.51\end{array}$ & $\begin{array}{r}1569.25 \\
685.17\end{array}$ & $\begin{array}{r}1619.50 \\
628.09\end{array}$ & $\begin{array}{r}1880.00 \\
931.75\end{array}$ & $\begin{array}{l}1760.12 \\
1035,61\end{array}$ \\
\hline
\end{tabular}




\section{TABLE 11}

Mann-Wtitney U-Tests: Number of Lever B Resporses ir Treatment Phase

\begin{tabular}{cccc}
\hline Group & DRO & $\mathrm{CC}^{\mathrm{D}}$ & $\mathrm{CC}^{\mathrm{S}}$ \\
ET & $\mathrm{U}=\mathbf{2 2}$ N. S. & $\mathrm{U}=7^{*}$ & $\mathrm{U}=0 * *$ \\
DRO & & $\mathrm{U}=26$ N. S. & $\mathrm{U}=0 * *$ \\
$\mathrm{CC}^{\mathrm{D}}$ & & & $\mathrm{U}=0 * *$
\end{tabular}

Number of Lever B responses were also examined in the Test phase. This analysis indicated that $\mathrm{CC}^{\mathrm{S}}$ Group continued responding on Lever $E$ at a high rate, even during this Phase where reinforcement for the alternative response was discontinued.

The analysis of Lever B responding in the Test Phase also yielded significant $t_{1}$ eierogeneity of variance $\left({ }^{F} \mathrm{MAX}=338.93\right.$, $\mathrm{p}<.001$ ). A Krushal-Wallis ANOVA by ranks yielded significant differences between the four groups on total number of Lever B responses during the rest Planje $(H=17,68, p<.001)$. Table 12 presents means and standard deviations for each group over the five test sessions, while the results of the Mann-Whitney U-Tests are presented in Table 13. 


\section{TABLE 12}

Mean Number and Standard Deviations of

Lever B Responses for each Group Over Test Sessions

\section{Session}

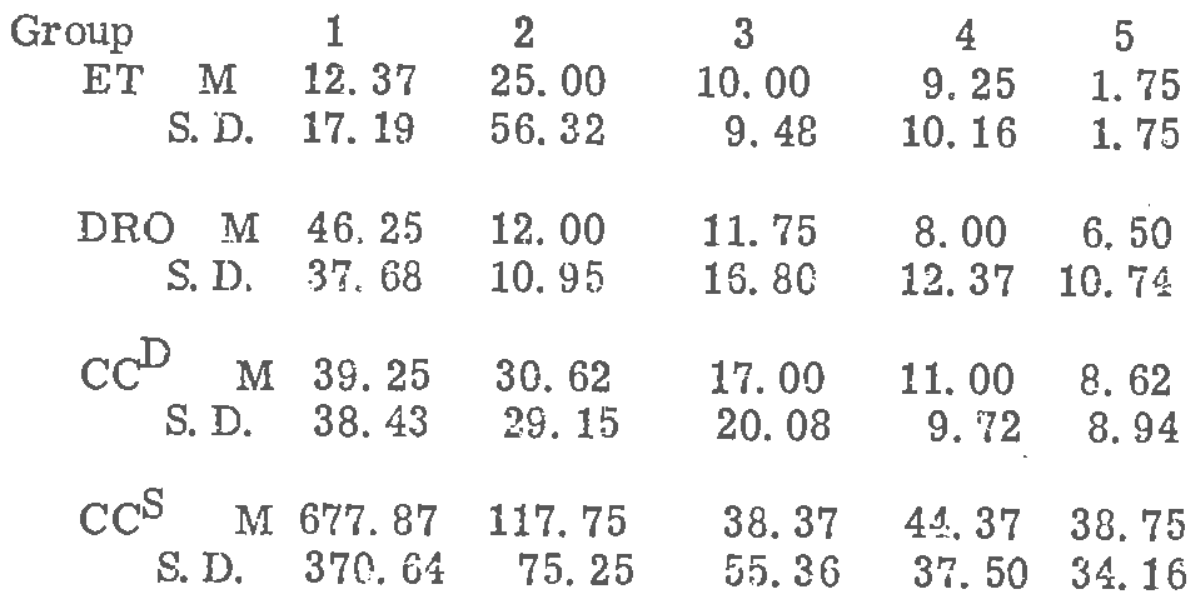

TABLE 13

Mann-Whitney U Tests: Number of Lever B Responses in Test Phase

$\begin{array}{clll}\text { Group } & \text { DRO } & \mathrm{CC}^{\mathrm{D}} & \mathrm{CC}^{\mathrm{S}} \\ \mathrm{ET} & \mathrm{U}=23 \text { N. S. } & \mathrm{U}=22 \text { N. S. } & \mathrm{U}=0 * \\ \text { DRO } & & \mathrm{U}=29 \text { N. S. } & \mathrm{U}=0 * \\ \mathrm{CC}^{\mathrm{D}} & & & \mathrm{U}=0 *\end{array}$

${ }^{*} p<.001$

An examination of Table 13 shows that during the Test Phase, the $\mathrm{CC}^{\mathrm{S}}$ Group again made significantly more Lever $\mathrm{B}$ responses than 
Fig. 6. Total Number of pole pushes during each day of training, treatment, and test phases. 


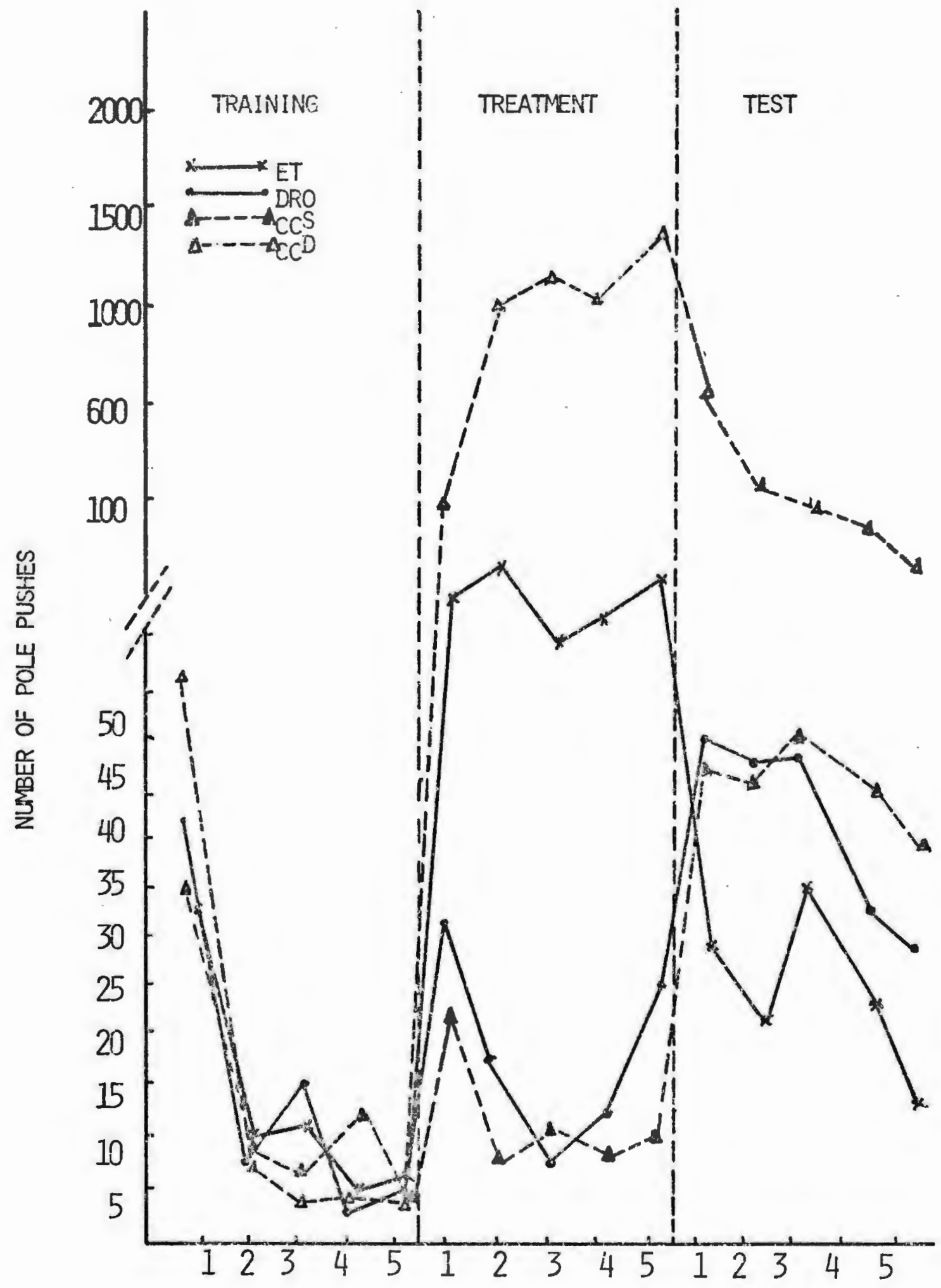

TRIALS 
each of the other three groups. No other significant differences between the other groups were observed.

The number of responses made on the suspended pole for each group during the Training, Treatment, and Test Phases were also analyzed. The Pole Push was the second alternative response available during the response elimination procedures. Figure 6 presents the course of the pole push during each of the three phases of the Experiment.

Means and standard deviations for number of pole pushes during the Training Phase are presented in Table 14.

TABLE 14

Mean Number and Standard Deviations of Pole Pushes for each Group During the Training Phase

Session

\begin{tabular}{|c|c|c|c|c|c|}
\hline $\begin{array}{l}\text { Eroup } \\
\\
\text { S. D. }\end{array}$ & $\begin{array}{c}1 \\
34.62 \\
24.51\end{array}$ & $\begin{array}{c}2 \\
10.00 \\
13.47\end{array}$ & $\begin{array}{l}3 \\
11.50 \\
21.44\end{array}$ & $\begin{array}{c}4 \\
\text { 4. } 62 \\
5.01\end{array}$ & $\begin{array}{c}5 \\
6.62 \\
9.47\end{array}$ \\
\hline 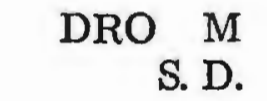 & $\begin{array}{l}14.12 \\
38.57\end{array}$ & $\begin{array}{l}7.62 \\
9.22\end{array}$ & $\begin{array}{l}14.00 \\
26.48\end{array}$ & $\begin{array}{l}\text { 2. } 12 \\
\text { 2. } 90\end{array}$ & $\begin{array}{l}5.00 \\
6.48\end{array}$ \\
\hline $\begin{array}{r}C^{D} \quad M \\
\text { S. D. }\end{array}$ & $\begin{array}{r}68.75 \\
114.85\end{array}$ & $\begin{array}{r}8.75 \\
11.32\end{array}$ & $\begin{array}{l}4.37 \\
5.09\end{array}$ & $\begin{array}{l}3.87 \\
5.70\end{array}$ & $\begin{array}{l}3.75 \\
3.80\end{array}$ \\
\hline 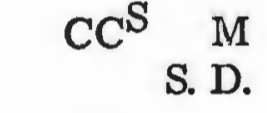 & $\begin{array}{r}36.62 \\
11.85\end{array}$ & $\begin{array}{l}14.62 \\
14.76\end{array}$ & $\begin{array}{l}\text { 4. } 50 \\
4.47\end{array}$ & $\begin{array}{l}13.12 \\
30.68\end{array}$ & $\begin{array}{l}4.12 \\
5.59\end{array}$ \\
\hline
\end{tabular}


During the Training Phase, all groups appeared to be pushing the pole at the same low, stable pate. To determine if there were any differences between the groups, total number of pole pushes were compared. During this Training Phase, significant heterogeneity of variance was present $\left({ }^{\mathrm{MAX}}=7.96, \mathrm{p}<.01\right)$. The Kruskal-Waliis ANOVA by ranks, however, yielded no significant differences ( $H=.580$ during this Phase.

An analysis of the number of pole pushes made in the Treatment Whase was also undertaken to determine the degree to which the alternate pole push response was emitied by each group. Table 15 presents means and standard deviations for each group over the five treatment sessions, and indicates that the $\mathrm{CC}^{\mathrm{D}}$ Group responded on the alternate pole at a very hign rate during the Treatment phase. The ET Group also was responding at a high level. In fact, the ET group responded on the pole the second most frequently during this phase. 


\section{TABLE 15}

Mean Number and Stancard Deviations of

Pole Pushes for Each Group during Treatment Phase

\section{Session}

\begin{tabular}{|c|c|c|c|c|c|c|}
\hline $\begin{array}{l}\text { Group } \\
\text { ET } \\
\end{array}$ & $\begin{array}{l}\text { M } \\
\text { D. }\end{array}$ & $\begin{array}{c}1 \\
84.37 \\
86.16\end{array}$ & $\begin{array}{c}2 \\
97.37 \\
159.97\end{array}$ & $\begin{array}{c}3 \\
65.37 \\
68.63\end{array}$ & $\begin{array}{c}4 \\
68.37 \\
78.00\end{array}$ & $\begin{array}{c}5 \\
86.00 \\
126.57\end{array}$ \\
\hline $\begin{array}{l}\mathrm{DRO}_{\mathrm{S}} . \\
\end{array}$ & $\begin{array}{l}\text { M } \\
\text { D. }\end{array}$ & $\begin{array}{l}32.50 \\
32.95\end{array}$ & $\begin{array}{l}17.75 \\
20.65\end{array}$ & $\begin{array}{r}8.00 \\
11.12\end{array}$ & $\begin{array}{l}14.00 \\
14.02\end{array}$ & $\begin{array}{l}26.25 \\
38.09\end{array}$ \\
\hline $\mathrm{CC}^{\mathrm{D}}$. & $\begin{array}{l}\text { M } \\
\text { D. }\end{array}$ & $\begin{array}{l}463.25 \\
374.53\end{array}$ & $\begin{array}{r}1529.82 \\
888.72\end{array}$ & $\begin{array}{r}1739.37 \\
931.55\end{array}$ & $\begin{array}{r}1640.00 \\
865.70\end{array}$ & $\begin{array}{r}2076.37 \\
908.76\end{array}$ \\
\hline${ }^{\mathrm{CC}^{\mathrm{S}}}$ & $\begin{array}{l}\text { M } \\
\text { D. }\end{array}$ & $\begin{array}{l}22.37 \\
28.97\end{array}$ & $\begin{array}{l}5.87 \\
6.74\end{array}$ & $\begin{array}{l}10.75 \\
12.03\end{array}$ & $\begin{array}{l}7.84 \\
8.74\end{array}$ & $\begin{array}{r}8.87 \\
10.07\end{array}$ \\
\hline
\end{tabular}

An analysis of the number of pole pushes made in the Treatment Phase again yielded heterogeneity of variance among the groups (FMAX $=3580.07, \mathrm{p}<.001$ ). The Kruskal-Wallis ANOVA by ranks indicated a significant difference in terms of total number of pole pushes made by each group during the Treatment Phase $(\mathrm{H}=21.29, \mathrm{p}<.001)$. Table 16 illustrates the differences observed with the Mann-Whitney U-Tests: the only two groups which did not differ in the Treatment Phase in total number of pole pushes were the $\mathrm{CC}^{\mathrm{S}}$ Group and the DFO Group. 


\section{TABLE 16}

Mann-Whitney U-Tests: Number

of Pole Pushes in Treatment Phase

$\begin{array}{cccc}\text { Group } & \mathrm{DRO} & \mathrm{CC} & \mathrm{CC} \\ \mathrm{ET} & \mathrm{U}=16 * & \mathrm{U}=0 * * * & \mathrm{U}=9 * * \\ \mathrm{DRO} & & \mathrm{U}=0 * * * & \mathrm{U}=23 \text { N. S } \\ \mathrm{CC}^{\mathrm{D}} & & & \mathrm{U}=0 * * *\end{array}$

\footnotetext{
$* \mathrm{p}<.05$

$*$ * $<.01$

$* * * p<.001$
}

The number of responses on this manirulandum during the Test Phase were also examined. Means and standard deviations for this Phase are presented in Table 17. This table reveals that the $\mathrm{CC}^{\mathrm{D}}$ Group made far more pole pushes in the Test Phase than any other group. 


\section{TABIE 17}

Mean Number and Standard Deviations

of Pole Pushes for Each Group during Test Phase

\section{Session}

\begin{tabular}{ccccccc} 
Group & & 1 & 2 & 3 & 4 & 5 \\
ET & M & 28.62 & 20.63 & 37.62 & 25.25 & 14.50 \\
& S. D. 30.94 & 30.21 & 38.34 & 28.19 & 27.16 \\
DRO & M & 60.62 & 50.00 & 53.50 & 36.12 & 32.87 \\
S. & D. 69.50 & 59.99 & 78.50 & 39.64 & 73.88 \\
\multicolumn{1}{c}{ CC } & & & & & & \\
& M & 1092.87 & 476.50 & 307.75 & 280.87 & 166.37 \\
& S. D. & 387.88 & 253.27 & 210.12 & 163.85 & 152.82 \\
CC & M & 66.37 & 63.25 & 68.50 & 51.87 & 42.00 \\
& S. D. & 32.10 & 57.29 & 60.70 & 47.59 & 41.36
\end{tabular}

A. statistical analysis of this phase yielded significant heterogeneity of variance between groups $\left({ }^{F} \mathrm{MAX}=338.93, p<.001\right)$. The Kruskal-Wallis ANOVA by ranks again resulted in significant differences between groups in total number of pole pushes made in the Test Phase $(\mathrm{H}=19.43, \mathrm{p}<.001)$. The results of the Mann-Whitney $\mathrm{U}$-Tests are presented in Table 18, and reveal that during the Test Phase Group ET did not differ from GROUP DRO, and Group $\mathrm{CC}^{\mathrm{S}}$ did not differ from Group DRO. Overall, ET Group made the fewest pole pushes in Test, while $\mathrm{CC}^{\mathrm{D}}$ made the most. DRO and $\mathrm{CC}^{\mathrm{S}}$ Groups were intermediate in number of pole pushes and were not significantly different. 
TABLE 18

Mann-Whitney U-Testi: Number of Pole Pushes in Test Phase

\begin{tabular}{|c|c|c|c|}
\hline Group & DRO & $\mathrm{CC}^{\mathrm{D}}$ & $\mathrm{CC}^{\mathrm{S}}$ \\
\hline $\mathrm{ET}$ & $\mathrm{U}=21$ N. S. & $\mathrm{U}=0 * *$ & $\mathrm{U}=12 *$ \\
\hline DRO & & $\mathrm{U}=0 * *$ & $\mathrm{U}=23 \mathrm{~N} . \mathrm{S}$. \\
\hline $\mathrm{CC}^{\mathrm{D}}$ & & & $\mathrm{U}=0 * *$ \\
\hline
\end{tabular}




\section{DISCUSSION}

The results of this experiment attest to the efficacy of the Differential Reinforcement of Other Esehavior procedure as a method of achieving response elimination. While the results do not show that the Differential Reinforcement of Other Behavior procedure, when compared to Counter-conditioning and traditional Extinction Training, is any faster in response elimination, they do support the position that Differential Reinforcement of Other Behavior, when maintained as a response elimination procedure, is significantly more durable in its effects. This offers strong support for the use of the Differentiai Reinforcement procedure as an applied technique, for when compared with traditional Extinction Training, a procedure commonly known as a most effective long-lasting technique, Differential Reinforcement of Other Behavior emerges as just as effective and possibly more durable. In addition, Differential Reinforcement when compared with traditional Extinction Training and two Counter-conditioning procedures, emerged as being as efficient and durable, and significantly more resistant to the instatement of the original response.

While Counter-conditioning an alternative behavior may serve to suppress original responding while reinforcement is in effect, the extinction of the alternate behavior is accompanied by an increase in emission of the original response. It appears that once 
the alternate behavior is extinguished, original responding occurs at a rate that may even be higher than its rate at the end of original training. The original Lever A Response then follows the traditional course of extinction, as suggested by the response prevention hypothesis of Grant (1964). As in Leitenberg et. al. (1973), no great advantage of counter-conditioning other than a rapid temporary suppression of responding was observed over that of traditional extinction.

This temporary suppression effect with the subsequent "rebound" in responding was not observed in the Differential Reinforcement of Other Behavior treatment. The extinction effect, accompanied by short bursts of increased responding, appears only until the organism pauses long enough to experience the reinforcer a few times. Once reinforcement for not responaing occurs, the Differential Reinforcement contingencies begin to operate in place of simple extinction. The response elimination is much more complete, and as evidenced during the Peconditioning Phase, in which the Differential Reinforcement of Other Behavior Group was significantly more resistant to the return of the original Lever A reinforcement contingencies.

The differential effects of the four response elimination procedures began to appear during the Treatment Phase, when the different contingencies were introduced. All groups decreased their 
responding at a steady rate. In this Phase there were no differences in overall number of responses over the five days between the four groups. The $C^{D}$ group made the fewest originai fuever A responses overall, (although not significantly fewer than the others) a finding that is not surprising in light of the results of Leitenberg et. al. (1970, 1973). Jeitenberg et. al. usually report that during this phase of the experimant the Counter-conditioning groups suppress responding significantly more than the traditional Exinction Training groups. It is surprising, however, that the present $\mathrm{CC}^{\mathrm{S}}$ Group did not suppress in the same way as observed in Leiterberg's studies. The Counter-conditioning groups Leitenberg employs are usually of the similar response variety. In each of his studies it is this group which is most suppressed during the treatment phase of the experiment. In this study, however, the $C^{S}$ Group was the least suppressed. It was even less suppressed, in terms of total rumber of responses made, than the ET and DRO Groups, although not statistically different from them. This discrepancy may be explained in terms cf differences between the present study and those of Leitenberg st. al. $(19 \% 0,1973)$ in programming the various response elimination procedures during the Treatment Phase of the Experiment. In Lejtenberg's work, the Counter-conditioning procedure is acconplished by providing the alternative response on an FR schedule of reinforcement, as it was in this study. 
Leitenberg, however, also programs a change over delay (C. O.D.), in which an aliernative response mado mithin five seconds of an original lever response is not reinforced decreasing the chance of chaining between the new and old responses. The subject is actually undergoing a five second "Time Out" period in which making an original response suspends reinforcement for the alternative response for five seconds. This procedure, in the author's opinion, is not a pure Counter-conditioning procedure, but a combination of Counterconditioning and Time Out. It seems that when this Change Over Delay is programmed, there is considerably more original response suppression, for both $\mathrm{CC}^{\mathrm{D}}$ and $\mathrm{CC}^{\mathrm{S}}$ Groups, than the traditional Extinction Training Group. In the present study, however, where no Change Over Delay was present, the CCS Group, for all practical purposes, made no fewer responses than the traditional Extinction Training or Differential Reinforcement Groups during the Treatment phase.

An examination of the number of responses made on the alternatè manipuianda during the Treatment Phase gives an indication of just what the subject was doing during each of the responseelimination procedures. The $\mathrm{CC}^{\mathrm{S}}$ Group, as expected, began pressing the alternate Lever $B$ at an extremely high rate once reinforcement was introduced for that response. The number of original responses emitted during this phase was considerable, suggesting 
that as an incompatible response, responding on another lever was not that effective. This may be contrasted with the results of the $\mathrm{CCD}^{\mathrm{D}}$ Group where the subjects, like those in the $\mathrm{CC}^{\mathrm{S}}$ Group, began responding on the pole at an extremely high rate during the Treatment Phase, but unlike the $\mathrm{CC}^{\mathrm{S}}$ Group they did not make many original Lever: A presses. This suggests that during the phase where reinforcement for the alternative behavior was being provided, the topography of the original response was an important determinant of the effectiveness of the Counter-conditioning procedure, as it was in Leitenberg's 1973 siuady. While the $\mathrm{CC}^{\mathrm{D}}$ Group was pushing the pole, it was very unlikely that they would return across the cage to press the Lever 4 , herce very few Lever A preases were emitted by this group during the Treatment Phase. The $\mathrm{CC}^{3}$ Group, however: vas making its attenative Lever press in close proximity to, and with a very similar topography to the original lever, and cue to generalization and possible adventitious chaining, many more original Lever A responses were noted, i. e. chaining was more likely. During the Treatment Fhase the behavior of the ET Group illustrated the classic effects of frustration during extinction, accompanied by increases in original responding at first, then increased general activity. On every treatment day but the first and the last, the ET Group made more original Lever A responses than 
any other group, although not significantly more. This occurred even though this group was no longer being reinforced on any manipulandum.

The most striking example of the increased activity of the ET Group was given by the number of pole pushes made by this group during the Treatment Phase. Again, no reinforcernent was given for pushing the pole, but the ET Group made significantly more of these responses than every other group except the $\mathrm{CC}^{D}$ Group during this phase. This fact suggests that the suspended pole may have been a measure of overall activity in the lever box. When observed, the IT subjects appeared to be closing the connection on the omuidirectionaj. suspencied pole by unintentionally brushing by it as they moved constantly around the cage. This resulted in making four to five times the number of pole responses as the DRO or $\mathrm{CCS}$ subjects over the five treatment days. The increased activity manifested by the ET Group may be directly related to the frustration of nonreward commonly experienced in a situation where the organism was previously being reinforced for some behavior and suodenly the reinforcement is discontinued. Frustration in tinis case may be accompanied by heightened emotionality and increased overall activity, which in the case of the ET Group was measured by number of "accidertal" pole pushes. 
than the other Groups during the Treatment Phase. It was only surpassed by the $\mathrm{CC}^{\mathrm{D}}$ Group in terms of suppression of the original response during the Treatment Phase. The DRO Group was not different from the $\mathrm{CC}^{\mathrm{D}}$ Group in number of Lever $\mathrm{B}$ responses during the Treatment phase, nor was it different from the $\mathrm{CC}^{\mathrm{S}}$ Group in terms of number of Pole Pushes during Treatment. This fact suggests that the DRO Group was low in terms of activity, which may be related to less frustration produced by this procedure compared to the ET Group. Alternatively, the DRO Group may have learned to stay near the food cup and wait for the food pellet, a form of superstitious behavior. The DRO Group learned rather quickiy to "not respond" on Lever A, and once the no-response contingencies took over, the effect seemed to generalize to the other manipulanda in the lever box and to general activity overall. It should be noted that pressing the other manipulanda during Treatment would not have prevented the DRO reinforcement. Yet, there was little such responding. In summary, during the Treatment Phase, little difference was noted hetween the four groups in terms of early efficiency of response elimination. The only significant difference was between the $\mathrm{CC}^{\mathrm{D}}$ Group and the ET Group.

The DRO Group in this study appeared to be more efficient in eliminating the response than the ET Group, a finding that disagrees with the results of UHL \& Garcia (1969), but supports the 
results of Zeiler (1971), which showed that DRO reduced responding faster than ET. The difference obtained in this study between DRO and $\mathrm{ET}$ in the Treatment Phase was not statistically significant. However, the superiority of the DRO treatment was evident from an examination of the four groups over the treatment sessions because of less responding on each day.

An examination of the Test Phase results indicates the relative durability of the response elimination procedures. As the studies of Leitenbert et. al. $(1970,1973)$ have noted, a significant rebound effect was observed in the $\mathrm{CC}^{\mathrm{S}}$ Group on the first day of Testing, where all manipulanda were placed on extinction. On this day, both DRO and ET Groups combined made only about $25 \%$ of the number of original Lever A presses as did the $\mathrm{CC}^{\mathrm{S}}$ Group, while DRO and ET made only $50 \%$ of the number of original Lever A presses as $\mathrm{CC}^{\mathrm{D}}$. (See Figure 3 ).

Overall, ET Group made the fewest Lever A respcnses during the Test Phase. On the first day of Test, the ET Group made significantly fewer original responses than the DRO Group, but after the second day of Test, these differences disappeared. Both ET and DRO Groups made significantly fewer original responses than the two Counter-conditioning Groups, which were not different overall during the Test Phase. 
during Treatment and Test combined indicate that ET and DRO were both significantly more suppressed than the Counter-conditioning Groups. Significantly more Lever A responses were made by the $\mathrm{CC}^{\mathrm{S}}$ and the $\mathrm{CC}^{\mathrm{D}}$ Groups than the ET and DRO Groups during the Treatment and Test Phase combined. These results support those of Leitenberg et.al. $(1970,1973)$ in terms of overall lack of durability in the Counter-conditioning paradigm as a response elimination procedure. DRO emerges as much more durable procedure than both Counter-conditioning procedures because fewer original responses were made overall in the Treatment and Test Phases combined for this group, although DRO does not serve to suppress respording initially as readily as the $\mathrm{CC}^{\mathrm{D}}$ procedures.

The Keconditioning session gives an important estimate of the durability of response elimination, as the subjects were returned to the original VI-30 second schedule of reinforcement on the original manipulandum. Here the efficacy of the DRO procedure stands out even more when compared to the traditional ET Group, from which during the previous three phases of the study it did not differ statistically, and both of the Counter-conditioning Groups from which it differed again. During this one hour session, four of the eight animals in the DRO Group did not even begin pressing the original lever until 36 minutes into the session. Overall, the DRO Group was much more resistant to the return of the original reinfor cement 
contingencies. Thus an important criterion for a durable method of response elimination is met by the DRO procedure. While DRO may not be as efficient as the other response elimination methods in terms of early suppression of the original bohavior, results in terms of durability reveal that DRO is just as durable as traditional Extinction Trainiag, and even more resistant to return of original contingencies of reinforcement than ET.

These results support those of Uhl \& Garcia (1969) and Sherman (1971), which show that DRO is a superior method of eliminating responding in terms of permanency of effects when compared to Extinction Training. This study also demonstrates, however, that DRO is a superior method of eliminating a response when compared to direct Counter-conditioning of an alternative behavior. This adds greatly to the results of Uh1 \& Garcia (1969) and to the results of Leitenberg (1973) in that the resuits of this study support the efficacy of DRO when directly evaluated with Extinction Training and Counter-conditioning at the same time.

In this experiment the DRO method of response elimination may be considered the best overall procedure when compared to ET, $\mathrm{CC}^{\mathrm{D}}$, and $\mathrm{CC}^{\mathrm{S}}$. As was expected, response elimination was no more rapid uncer DRO than under any of the other, procedures because of the reinforcement for not responding which occurs in DRO. The discriminative effect of $\mathrm{S}^{\mathrm{R}}$ may have continued to control original 
responding during the Treatmont Phase to a certain degree since the reinforcing event for not responding in DRO was the same reinforcer used to condition the response in Training before the introduction of DRO. Each subject had been trained to return to the Lever A and resume pressing after receiving the reinforcement, and this behavior continued when DRO was initially introduced.

Although systematic observation was not made, occasional observation of individual subjects suggested that very few reinforcements for not responding were necessary before the animal lowered his general activity and remained relatively motionless next to the food cup. This effect, according to Unl and Garcia, may be one disadvantage of the DRO procedure, i. e. no particular competing response is reinforced. Instead, the whole class of behaviors iajentified by exclusion as rot responding is reinforced. In this way, DRO resembles closely a superstition paradigm in which many other "unintenticnal" behaviors may be conditioned in place of the original response.

If one examines this procedure with an orientation towards direct application to human behavior, this effect may not be detremental at all. It may instead enharice new learning. In the traditional ET procedure, whether in the human applied setting or in the animal analogue, there is no programmed consequenee for not responding, hence the organism really gains nothing for cessation of 
responding. In the DRC procedure response cessation has a reinforcing consequence, hence the or oranism is experiencing positive, success-related stimuli, which are necessary and conducive to new learning. The concomitant of this experience is that frustration is reduced, and new learning may be accentuated rather than attenuated.

Overall, the results of this study show that DRO is, when evaluated directly agaiust three other methods of response eimination, a superior method of eliminating a response which has been learned. The four response elimination mellods have been compared in one study, and since this comparison had been previousiy aksent. from the literature concernitig response elimination, a contribution has been made to the findings of Leitenterg, Uhl $\&_{c}$ Garcia, and others. Their findings, in part, have been replicated, and even more important, have been compared directly with one another in a single study. This study, therefore, extends the demonstrated efficacy of the DRO procedures to the degree that when they are compared with traditional Extinction Training and two forms of Counter-conditioning the DRO procedure, is the most effective in maintaining the elimination of the learned response, even though it may not be the quickest method of achieving response elimination initially. 

Two Factor Mired Design

Analysis of Variance Summary Tabie

Number of Lever A Responses in Training Phase

\begin{tabular}{lrrrrrl}
\hline Source & Sums of Squares & df & Mean Square & F & \\
& & & & & & \\
Total & $23,919,517$ & 159 & & & \\
Between & $5,476,339$ & 31 & & & \\
$\quad$ Conditions & 642,215 & 3 & 214,072 & 1,239 & N. S. \\
$\quad$ Error & & $4,834,124$ & 28 & 172,647 & & \\
Within & $21,443,178$ & 128 & & & \\
$\quad$ Trials & $10,852,182$ & 4 & $2,713,046$ & 30.615 & p <. 001 \\
$\quad$ Trials x C & 666,929 & 12 & 55,577 & .627 & N. S. \\
$\quad$ Error & $9,924,067$ & 112 & & & \\
& & & & & & \\
\hline
\end{tabular}




\section{APPENDIX B}

Mears Number of Responses for Each Subject on Each Manipulandum for Training Treatment and Test 
Mean Number of iever A Responses for Each Subject During Treatment and Test and Total Number of Lever A Responses for Each Subject in Reconditioning:

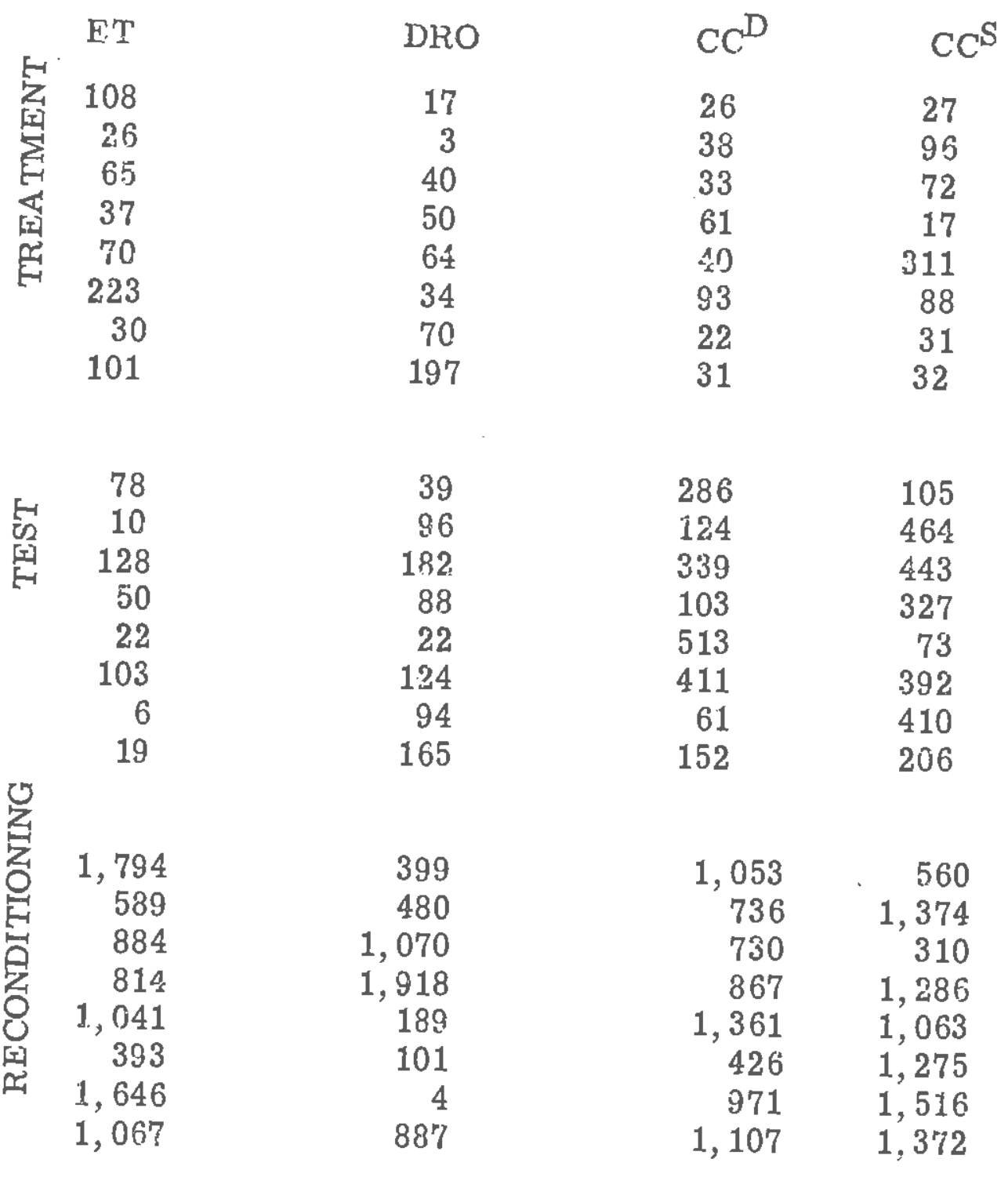


TABLE 2

Mean Number of Lever B Responses for Each Subject During Training, Treatment and Test Phases

\begin{tabular}{|c|c|c|c|}
\hline ET & DRO & $\mathrm{CC}^{\mathrm{D}}$ & $\mathrm{CC}^{\mathrm{S}}$ \\
\hline 217 & 19 & 100 & 48 \\
\hline 53 & 9 & 22 & 69 \\
\hline 108 & 122 & 35 & 111 \\
\hline 141 & 45 & 22 & 72 \\
\hline 21 & 6 & 31 & 86 \\
\hline 1 & 54 & 6 & 25 \\
\hline 36 & 48 & 122 & 179 \\
\hline 31 & 61 & 18 & 57 \\
\hline
\end{tabular}

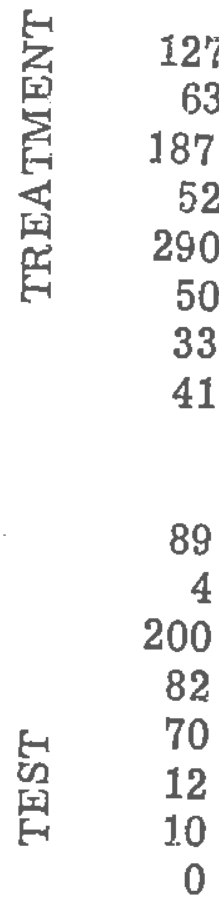

5
5
210
65
11
83
31
65

$\begin{array}{rr}15 & 4,754 \\ 24 & 10,129 \\ 38 & 3,959 \\ 38 & 6,205 \\ 28 & 6,611 \\ 1 & 14,043 \\ 100 & 8,288 \\ 29 & 6,850\end{array}$

89

00

82

70

12

10

56

7
138

113

17

55

139

152

$\begin{array}{rr}58 & 514 \\ 56 & 1,390 \\ 256 & 834 \\ 35 & 733 \\ 131 & 155 \\ 3 & 1,537 \\ 226 & 1,294 \\ 87 & 880\end{array}$


TABLE 3

Mean Number of Pole Pushes for Each Subject During Training, Treatment and Test Phases

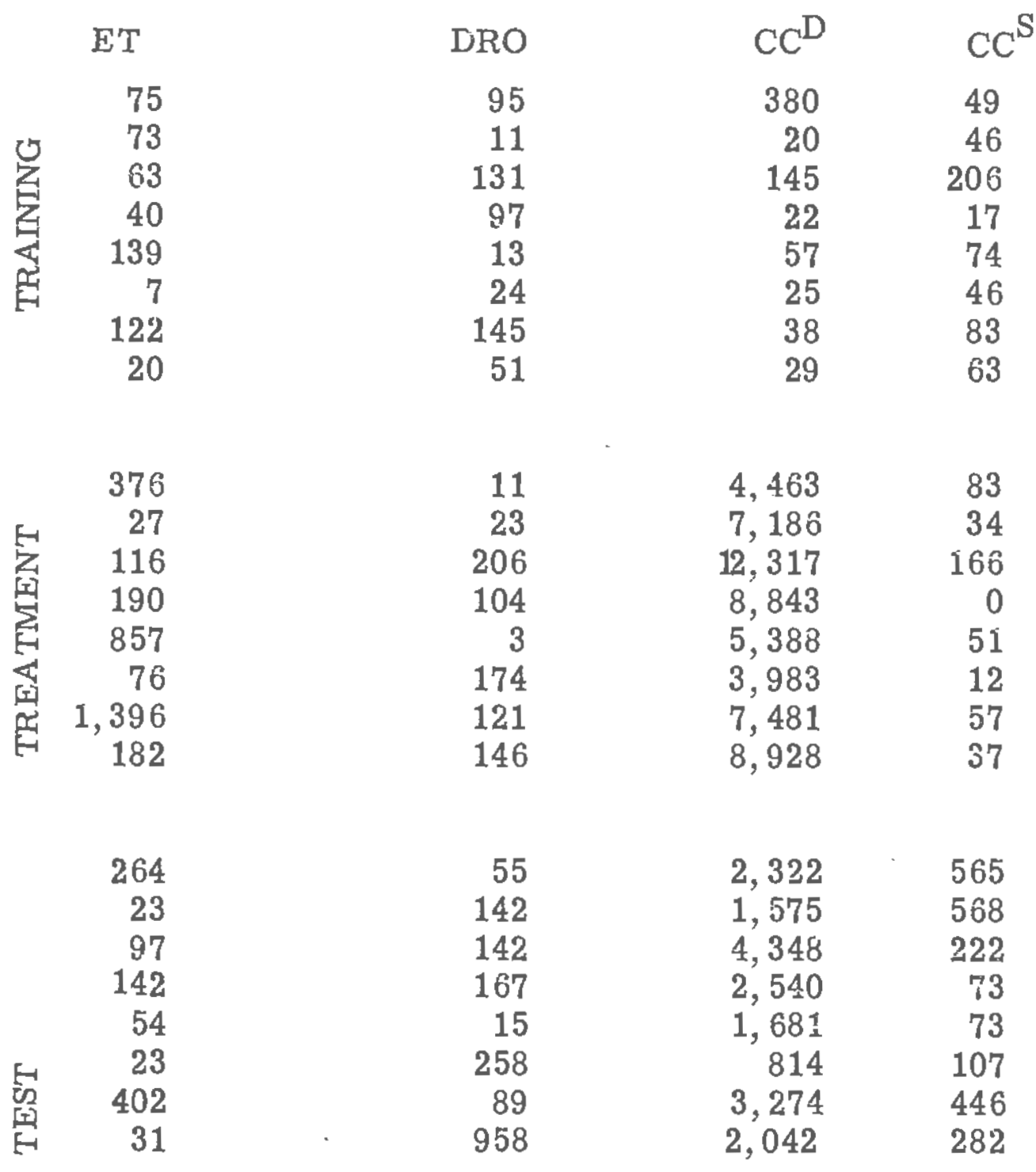


Amsel, A. The role of frustrative non-rexard in continuous reward situations. Phychological Bulletin, 1958, 55, 102-119.

Boe, E. \& Church, R. I. Permanent effects of punishment during extinction. Journal of Comparative and Physiological Psychology, 1967, 63, 486-492.

Boe, E. Extinction as a function of intensity of punishment, amount of training and reinforcement of a competing response. Canadian Journal of Psychology, 1964, 18, 328-342.

Catania, A. C. Concurrent operants. I. W. K. Honig (Ed.), Operant Behavicr: areas of research and application, New York, Appelton-Century-Crofts, 1966.

Catania, A. C. Concurrent performances: Inhibitions of one response by reinforcement oî another. Journal of the Experimental Analysis of Behavior, 1969. 12, $\overline{731}-\overline{74} 4$.

Deese, J. \& Hulse, S. H. The Psychology of Learning, N. Y.: · McGrawr-Hill, 1967.

Denny, M. R. Relaxation theory and experiments. In F. R. Brush (Ed.), Aversive Conditioning and learning; N. Y.: Academic Press, 1971

Enkema, S., Slavin, R. Spaeth, C. \& Neuringer, A. Extinction in the presence of free food. Psychonomic Science, $1972,26,267-269$.

Grant, D. A. Classical and operant conditioning. in A. W. Melton (Ed.), Categories of human learning. New York: Academic Press, 1964.

Guthrie, E. R. The Psychology of Learning; Harper, 1952.

Hays, W. Statistics. New York: Holt, Rinehart and Winston, $196 \overline{3 .}$ 
Johnson, D. L. McGlynn, F. D., \& Topping, J. S. The relative efficiency of four response elimination techniques following VR reinforcement training. Psychological Record, 1973, 23, 203-208.

Kimble, G. A. Higard and Marquis conditioning and learning. New York: Appleton-Century-Crofts, 1961.

Koppenal, R. J. and Jagoda, E. Proactive inhibition of a maze position habit. Journal of Experimental Psychology, 1968, $76,664-668$.

Leitenberg, H. , Rawson, R. , \& Bath, K. Reinforcement of competing behavior during extinction. Science, 1970, $169,301-303$.

Leitenberg, H. Rawson, R. Reinforced alternative behavior during punishment and extinction with rats. Journal of Comparative and Physiological Psychology. 1973, 85, 593-600.

Leitenberg, Rawson \& Mulick, Extinction and reinforcement of alternative behavior in rats and pigeons. Journal oî Comparative and Physiological Psychology, 1974 In Press.

Mulick, J. A. Reinforcement frequency for alternative behavior in extinction with pigeons. Paper presented at 44th Annual Meeting of the E. P. A., Washington, D. C. May, 1973.

Uhl, C. \& Sherman, W. Comparison of combinations of omission, punishment, and extinction methods in response elimination in rats. Journal of Comparative and Phsysiological

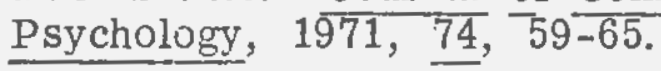

Uhl, C. \& Garcia, E. Comparison of omission with extinction in response elimination in rats. Journal of Comparative and Physiological Psychology, 1969, 69, 554-562.

Weinstock, S. Resistance to extinction of a running response following partial reinforcement under widely spaced trials. Journal of Comparative and Physiological Psychology, $1964,47,318-323$. 
Zeiler, M. D. Elimination of behavior with reinforcement. Journal of Experimental Analysis of Behavior, 1971, 16, $401-405$. 